\title{
On the representation of sea ice in global ocean general circulation models
}

\author{
Achim Stössel \\ Department of Oceanography, Texas A\&M University, College Station
}

Josef M. Oberhuber

Deutsches Klimarechenzentrum, Hamburg, Germany

Ernst Maier-Reimer

Max-Planck-Institut fur Meteorologie, Hamburg, Germany

\begin{abstract}
The performance of the sea ice component of two ocean general circulation models (OGCMs) is investigated under quasi-identical forcing and boundary conditions and compared with the performance of a state-of-the-art stand-alone sea ice model. The latter reproduced realistic sea ice characteristics under the same external conditions. All three sea ice models employ a viscous-plastic constitutive law to describe the variation in internal ice stress in the momentum balance. The individual thermodynamic formulations were unified to provide consistent reference versions for this investigation. The sea ice models are compared under various conditions to detect first-order discrepancies. Finally, the treatment of the sea ice component in global OGCMs is discussed in a more general context, illustrating the effect of some simplifications commonly used in OGCMs. We focus on the Southern Ocean, where sea ice plays a critical role in bottom water formation. Our studies show that sea ice in present-day global OGCMs can be formulated with the same quality as stand-alone sea ice models designed for specific regional studies, without the sacrifice of notable extra computation time. A standardization of both the dynamic and the thermodynamic part of an OGCM sea ice component turns out to be necessary to prevent unrealistic upper boundary conditions in forced OGCM simulations and distorted sensitivities in coupled simulations.
\end{abstract}

\section{Introduction}

From the beginning of climate change studies with coupled atmosphere-ocean general circulation models (A-OGCMs) it was obvious that sea ice plays a crucial role in the performance of the simulations in high latitudes [e.g., Meehl and Washington, 1990; Manabe et al., 1992; Cubasch et al., 1992, 1994]. Sea ice is a highly sensitive variable in coupled GCM simulations. In fact, sea ice indicates the skill of such simulations in terms of a proper transfer of momentum, heat, and mass between the respective media.

In addition to questions concerning the treatment of the boundary layers at the coupling interface [e.g., Stössel, 1992] and problems concerning the incorporation of subgrid-scale phenomena due to heterogeneous sea ice distributions within GCM-scale grid cells [e.g., Stössel and Claussen, 1993], the physical description of sea ice in coupled GCMs is decisive. During recent years there has accordingly been some effort to improve the sea ice component in coupled GCMs. Such improvements are mainly based on simulation experiences with dynamic-thermodynamic sea ice models coupled to regional OGCMs [e.g., Hibler and Bryan, 1987; Semtner, 1987; Piacsek et al., 1991; Häkkinen and Mellor, 1992], mainly with focus on the Arctic Ocean.

Copyright 1996 by the American Geophysical Union.

Paper number 96JC01583.

0148-0227/96/96JC-01583\$09.00
For coupled GCMs with emphasis on global climate change studies, sea ice dynamics have usually been treated in a rather simplistic manner [Manabe et al., 1992; Cubasch et al., 1994]. Recently, sea ice dynamics have been improved by implementing the "cavitating-fluid" formulation into global coupled AOGCMs [e.g., Pollard and Thompson, 1994]. This approach, introduced by Flato and Hibler [1992], neglects the shear stresses, thus reducing the computational burden, while still yielding acceptable results, except for local ice drift in strong shear zones.

A more comprehensive representation of the sea ice dynamics on large scales is given by the viscous-plastic constitutive law introduced by Hibler [1979] to determine the variation in internal ice stress. It is part of the momentum balance and derived from first principles of rheology. This description is meanwhile employed in two global OGCMs, which are also used for coupled climate studies, namely, the "ocean isopycnal" (OPYC) model [Oberhuber, 1993a, b; Holland et al., 1993; Lunkeit et al., 1996] and the "Hamburg ocean primitive equation" (HOPE) model [Wolff and Maier-Reimer, 1993; Latif et al., 1994; Drijfhout et al., 1996; Legutke et al., 1996]. Specifically, the dynamic parts of the respective OGCM sea ice components were reformulated (from scratch) following Hibler [1979]. This was done in order to make the code consistent with the numerical schemes of the respective OGCM. The treatment of the thermodynamic processes was largely based on individual formulations [Oberhuber, 1993b; Maier-Reimer et al., 1993].

In this study, we generate a consistent reference version by 
replacing the respective thermodynamic formulations by the more common description used in the stand-alone "sea iceboundary layer" (SIBL) model [Stössel and Owens, 1992; Lemke et al., 1990]. The SIBL model is also used as a verification basis for the OGCM sea ice models. The SIBL simulations revealed promising results with appropriate forcing fields [Stossel, 1992]. Also, a series of sensitivity studies with varying model parameters and forcing conditions were conducted with this model [Stössel et al., 1990; Owens and Lemke, 1990; Stössel, 1991]. In these studies the model results were verified against various observations [e.g., Zwally et al., 1983; Gloersen and Campbell, 1988; Wadhams et al., 1987].

Our approach is to compare and to analyze the performance of the two OGCM sea ice models under identical boundary and forcing conditions. The emphasis of this study is to consider sea ice components of OGCMs which are used for global climate studies and where the sea ice physics are comprehensive enough to be comparable with state-of-the-art stand-alone sea ice models. We believe this kind of studies are necessary to increase the meaningfulness of GCM-scale climate modeling results. As yet, the (climate) modeling community relies heavily on such models, which in a combination of a variety of climate components (global coupled models) is supposed to represent the most powerful tools for climate predictions [Intergovernmental Panel on Climate Control (IPCC) 1995]. Systematic comparisons and verifications have so far been undertaken for different A-OGCMs within the Atmospheric Model Intercomparison Project (AMIP) project [Gates, 1995] and are definitely also required for other climate components used in comprehensive global coupled models.

In contrast to most earlier sea ice studies, we focus on the Southern Ocean, where the ice cover mostly consists of first-year ice and extends in wintertime to the largest area influenced by sea ice on Earth. In the northern hemisphere, deep-penetrative convection, which may eventually lead to deep-water formation, occurs mainly in the GreenlandIceland-Norwegian (GIN) Sea, where it is mostly triggered by surface cooling, while freshening due to precipitation or sea ice export from the Arctic Ocean reduces the overall convection rate [e.g., Mysak et al., 1990]. Thus, in the GIN Sea, local sea ice freezing does not seem to directly affect deep-water formation [e.g., Häkkinen, 1995]. In the mostly marginally stable Southern Ocean, on the other hand, freezing processes with subsequent brine rejection do play a substantial role in deepwater (bottom water) formation, thus modifying the thermohaline circulation [Gordon and Huber, 1990); Martinson, 1990; Toggweiler and Samuels, 1993]. In fact, the impact of Southern Ocean sea ice was recently subject to a somewhat controversial discussion about the role of sea ice in OGCMs. While Broecker [1986], based on $\delta^{1 /} \mathrm{O}$ data, argued that brine rejection due to Southern Ocean sea ice formation would lead to a local salinity enhancement of nearly $0.9 \mathrm{psu}$, this is, based on shelf hydrography studies and employing the Geophysical Fluid Dynamics Laboratory (GFDL) OGCM, questioned by Toggweiler and Samuels [1995], who came up with a maximum sea ice induced enhancement of $0.2 \mathrm{psu}$. Which value to use to correct the surface salinity forcing of a global OGCM has a substantial impact on the water mass representation in an OGCM (England [1993], also using the GFDL OGCM), on the thermohaline circulation (THC) in terms of the Southern Ocean meridional overturning cell, and on the strength of the Antarctic Circumpolar Current (ACC) (e.g., England [1992] and Drijfhout et al. [1996], using the HOPE OGCM). Finally, Southern
Ocean sea ice also seems to modify THC variability, as was recently pointed out by Pierce et al. [1995] in an experiment with the global large-scale geostrophic (LSG) OGCM [MaierReimer et al., 1993]: THC oscillations were excited by imposing that the sea ice salinity stays at $35 \mathrm{psu}$, thus deactivating the brine rejection mechanism. With brine rejection, there were no THC oscillations, leading Pierce et al. to argue that this process stabilizes the water column (at least according to the way brine was distributed in the OGCM).

None of the above studies raises the question on how realistically the sea ice component is configured in the respective OGCMs, nor do these studies address the importance of realistic atmospheric forcing of the sea ice, both of which is known to be of leading-order importance for reasonable sea ice simulations [e.g., Walsh et al., 1985; Stössel et al., 1990]. In this study we use daily varying fields derived from a numerical weather prediction (NWP) model composed in earlier studies with the SIBL model. In a step-to-step decomposition of the two OGCM sea ice components we reveal the most sensitive assumptions and analyze their validity. The decisive strategy in this approach is to separate the individual sea ice components from the respective OGCM and to provide quasi-identical boundary and forcing conditions for an objective comparison. Subsequently, we perform sensitivity studies with the SIBL model in order to investigate the effects of some of the most commonly used simplifications in OGCMs.

First, the original formulations of the OPYC and HOPE OGCM sea ice components are presented in relation to the SIBL sea ice model. Details are given in Appendices B and C. The performances of the adjusted sea ice models are compared to those of the SIBL sea ice model. The following more detailed analysis is structured in a hierarchy of experiments investigating the dynamic and thermodynamic performances of the two OGCM sea ice models separately. This is followed by a section on the possible impact on the ocean, and by two sections studying the impact of different assumptions on the dynamic forcing and on new-ice formation in partially icecovered grid cells. The paper concludes with a summary including some recommendations for sea ice modeling in GCMs.

\section{Models and Configuration}

The sea ice model used for verification constitutes the core of the SIBL model system. It is based on the version of Hibler and Ackley [1983] modified and upgraded by Lemke et al. [1990], Owens and Lemke [1990], and Stössel [1992] (Appendix A). The additional routines optionally provided in SIBL for a prognostic oceanic mixed layer and an interactive atmospheric boundary layer are not used in this study, since we are focusing here on the description of sea ice itself. The OPYC and HOPE sea ice models are extracted from the respective ocean code and investigated separately.

It is beyond the scope of this paper to describe all details of each individual model. The essential characteristics and differences of the respective OGCM sea ice formulations versus SIBL are described in Appendices B and C. Further details are given by Hibler [1979], Lemke et al. [1990], and Stössel and Owens [1992] for SIBL; Oberhuber [1993a, b] and Holland et al. [1993] for OPYC; and Wolff and Maier-Reimer [1993] and Drijfhout et al. [1996] for HOPE.

To compare the performance of the OGCM sea ice models with that of the SIBL model, the same Southern Ocean boundary and forcing conditions as described by Stössel [1992] are 
applied to the three models. The air-ice fluxes of momentum, heat, and moisture are determined via standard bulk formulae. The vertical oceanic heat flux is assumed to be zero and the oceanic mixed layer is kept at a constant depth of $60 \mathrm{~m}$. The atmospheric forcing is derived from daily values of air temperature, relative humidity, surface pressure, and wind fields obtained from two years (1985 and 1986) of the daily global analyses of the European Center for Medium Range Weather Forecasts (ECMWF). Other forcing data are derived from climatological data, either monthly means (precipitation) or annual means (cloudiness, geostrophic ocean currents).

The models are run on a latitude-longitude grid; the SIBL and OPYC sea ice models employ a B grid with $2.5^{\circ}$ latitudinal and $5.0^{\circ}$ longitudinal resolution. The translation from the $B$ grid to the E grid of the HOPE sea ice model was performed in such a way that all vector points of the HOPE grid correspond exactly to all points (i.e., vector and scalar points) of the $B$ grid used in the other two models. This yields a factor $\sqrt{2}$ higher grid resolution in the HOPE model [Arakawa and Lamb, 1977]. Thus the external conditions are not exactly the same for all three models, leading to the expression "quasiidentical." The time step is 1 day. The computational domain covers the entire region south of $50^{\circ} \mathrm{S}$. The ECMWF atmospheric data from 1985 are used for 5 consecutive years in order to arrive at a cycle-stationary equilibrium, while the results shown are associated with the atmospheric forcing from the year 1986 used for the sixth simulation year.

In order to investigate the individual dynamic performances, consistent reference sea ice model configurations were created by combining SIBL thermodynamics and OPYC dynamics (called SIOP), as well as SIBL thermodynamics and HOPE dynamics (called SIHO). Conversely, to analyze the thermodynamic behavior, these versions were compared with the original OPYC and HOPE sea ice models.

In this study we focus on any differences among the respective simulations, defining the SIBL simulations as the most realistic response against which the performance of the OGCM sea ice components are verified. The large-scale spatial ice thickness pattern is the most informative quantity for estimating the skill of a sea ice simulation. It mirrors the integrated effect of ice drift and thermodynamics. Unfortunately, observations provide only sparsely distributed local measurements of (level) ice thickness. The SIBL simulations, having been verified against such measurements and other available observations earlier, provide the comparison material for this assessment study.

\section{Experiments}

\subsection{Dynamic Performance}

As mentioned earlier, the dynamics of the three sea ice models all make use of the viscous-plastic constitutive law introduced by Hibler [1979]. As shown in the appendices, there are, however, some differences in the mathematical and numerical formulations. We will thus investigate the dynamic behavior of both OGCM sea ice models in comparison to that of SIBL. Results of the SIBL simulation are shown in Figure 1 in terms of summer (S) and winter (W) spatial ice thickness patterns.

In order to avoid any influences from the differing thermodynamic treatments of the original codes, both the OPYC and HOPE thermodynamics have been replaced by those of SIBL, leading to the reference configurations SIOP and SIHO, men-
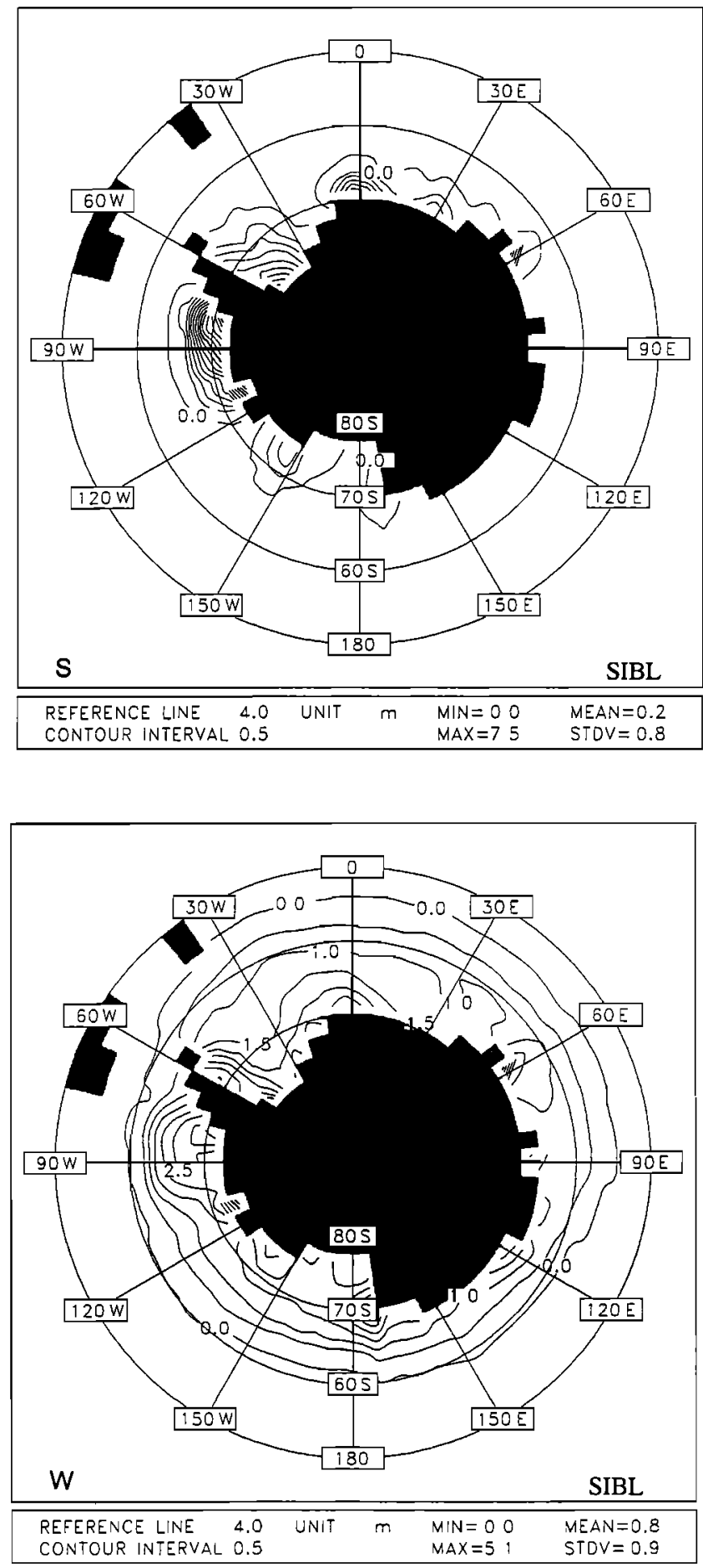

Figure 1. (top) Summer (S) and (bottom) winter (W) ice thickness pattern resulting from dynamic-thermodynamic simulations with the SIBL sea ice model.

tioned above. This combination yields the results shown in Figures $2 \mathrm{a}$ and $2 \mathrm{~b}$, which are directly comparable to Figure 1.

A comparison of the individual performances shows a high degree of similarity in representing the characteristic ice thickness distribution around Antarctica. The OPYC dynamics yield slightly higher ridging in convergent regions (in the western Weddell Sea, at the Greenwich meridian, off Victoria Land, and in the Bellingshausen Sea) than the SIBL dynamics, 

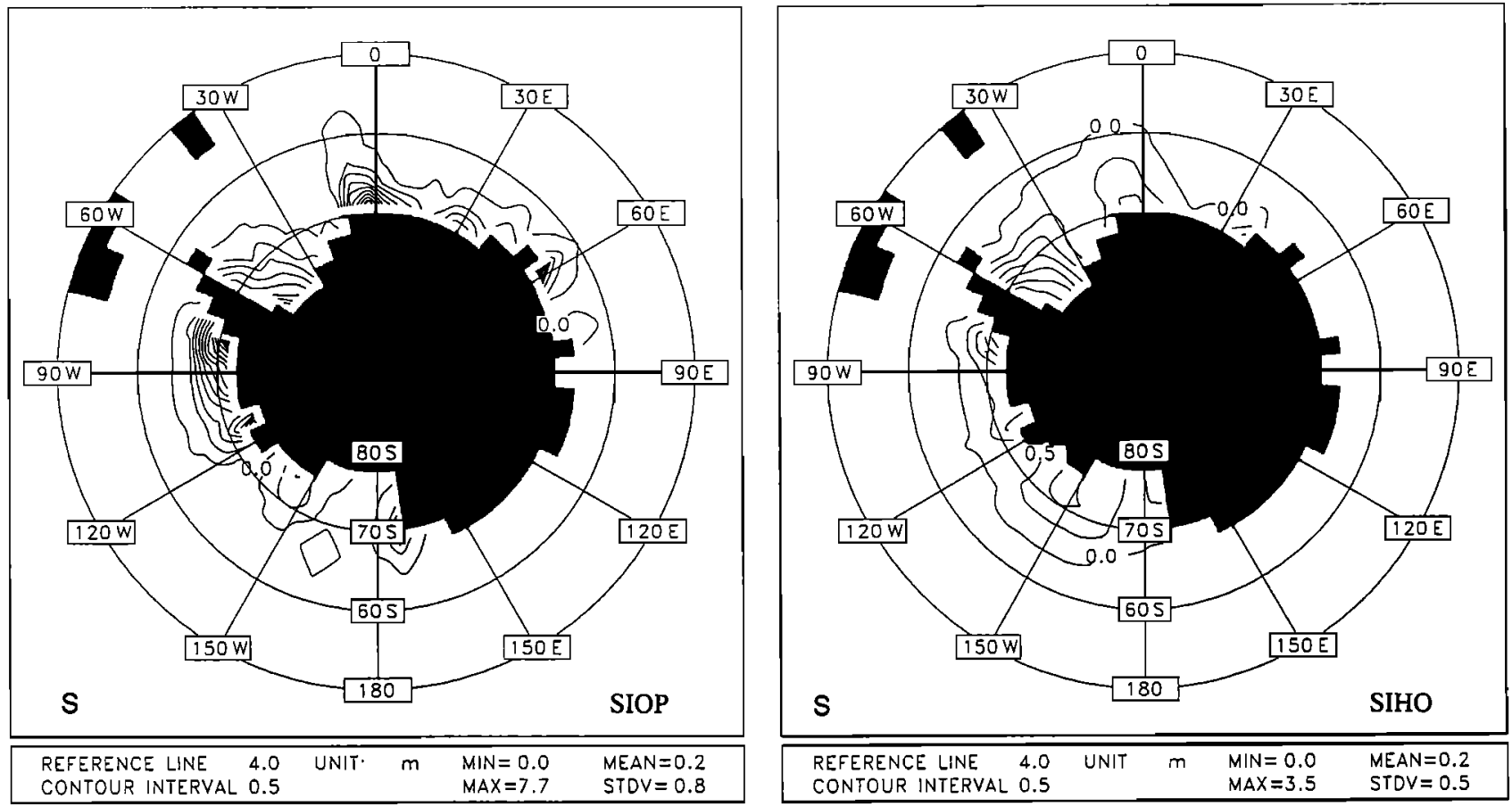

a

b
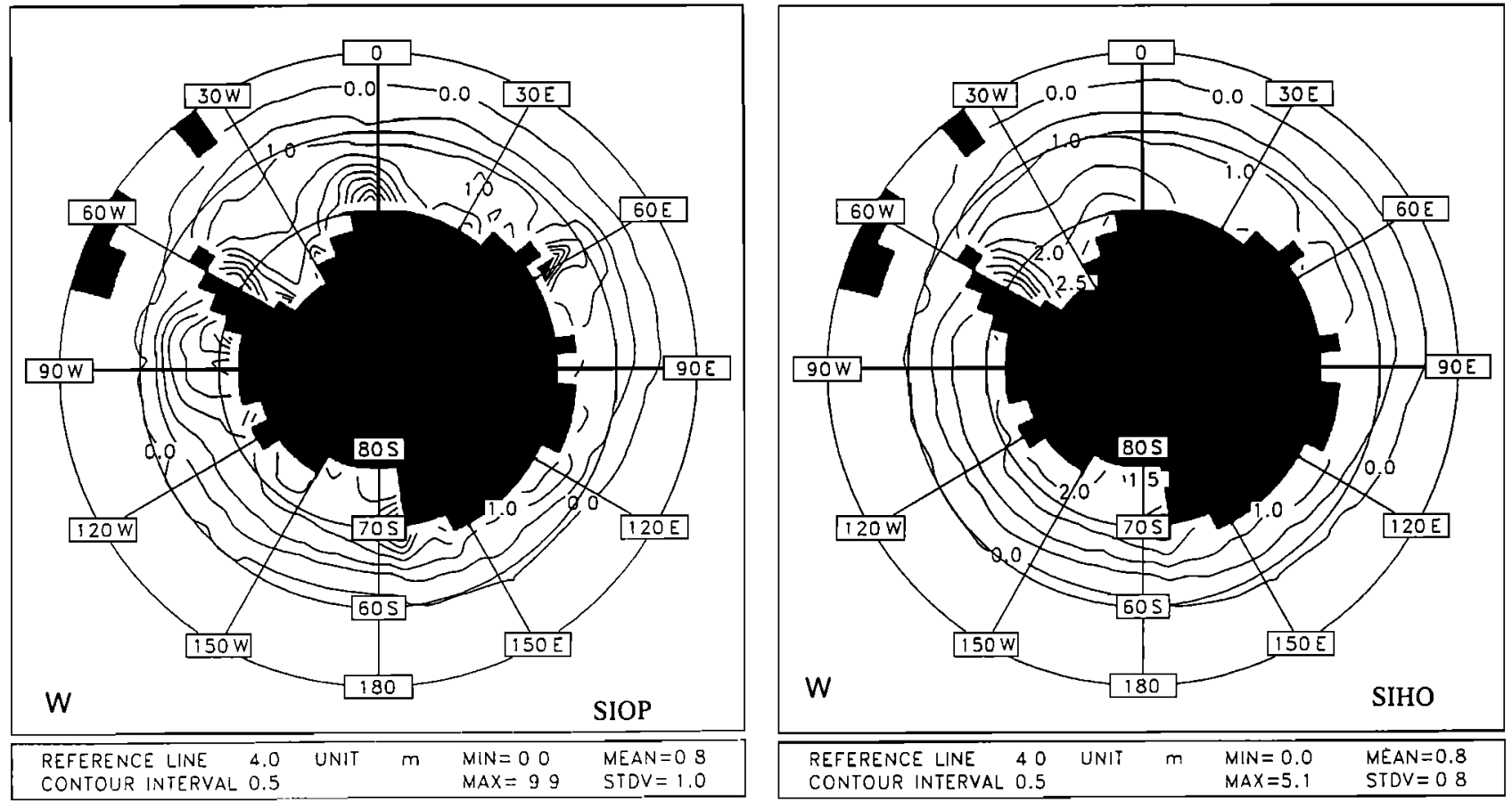

Figure 2. Results from simulations with (a) the combined SIBL thermodynamics-OPYC dynamics (SIOP) sea ice model and (b) the SIBL thermodynamics-HOPE dynamics (SIHO) sea ice model; otherwise as Figure 1.

while the opposite occurs with the HOPE dynamics. Specifically, the HOPE sea ice dynamics do not capture some of the ridging areas identified with SIBL and OPYC dynamics.

The latter discrepancies arise from the treatment of ice advection in HOPE. Ice thickness and ice compactness (and in the SIHO version also snow thickness) are advected with the ice velocity making use of an upstream scheme (as, e.g., described by Bacastow and Maier-Reimer [1990]). Since this represents a rather diffusive scheme, there is a tendency to smooth horizontal variations, originating, e.g., from ridging processes. Figure 3 illustrates a result for the winter situation achieved with a centered difference scheme in space together with a forward-backward difference scheme in time and by adding diffusion with spatially varying diffusion coefficients, both similar to what is used in SIBL. Local ice accumulations due to ridging processes, as simulated by SIBL in the Bellingshausen Sea and off Victoria Land, are now captured more realistically. In order to analyze the dynamic behavior of each model in 
more detail we investigate the models' behavior under the extreme situation of zero wind stress and no ocean currents. The only remaining active force term is the internal ice stress, which in this special case acts as a restoring force in response to the horizontally varying ice strength $P$ (equation (B4)), which is essentially a function of the ice thickness [Hibler, 1979]. As will be shown later, the ice motion produced in the low strain rate regime is highly dependent on the specification of the maximum viscous creep rate (in equation (B5) in Appendix B), which determines the transition from viscous to plastic flow [Leppäranta and Hibler, 1985].

For this set of sensitivity experiments we again used the SIOP and SIHO reference configurations. The results for the winter ice thickness distribution with zero dynamic forcing are presented in Figure 4 for SIBL, in Figure 5a for SIOP, and in Figure 6a for SIHO. With zero external dynamic forcing the results are expected to be similar to the results of pure thermodynamic experiments, i.e., ice thickness contours distributed zonally around the pole (see section 3.2). Indeed, this is well reproduced in the corresponding SIBL experiment (Figure 4), the residual ice velocities (up to $1 \mathrm{~cm} / \mathrm{s}$ ) leading to a somewhat higher ice volume than in a pure thermodynamic experiment.

Under these circumstances, however, the corresponding SIOP (Figure 5a) and SIHO (Figure 6a) simulations show quite different patterns than SIBL does. For the case involving the original OPYC sea ice dynamics, most of the difference is explained by the different calculations of the ice viscosities (equations (B5) and (B6)) as compared to the original formulation of Hibler [1979]. Subtle differences in the maximum viscous creep rate and the introduction of the latitudedependent coefficients for the zonal derivatives describing the yield curve for plastic flow have a major impact under the present conditions. Using the original formulations of Hibler

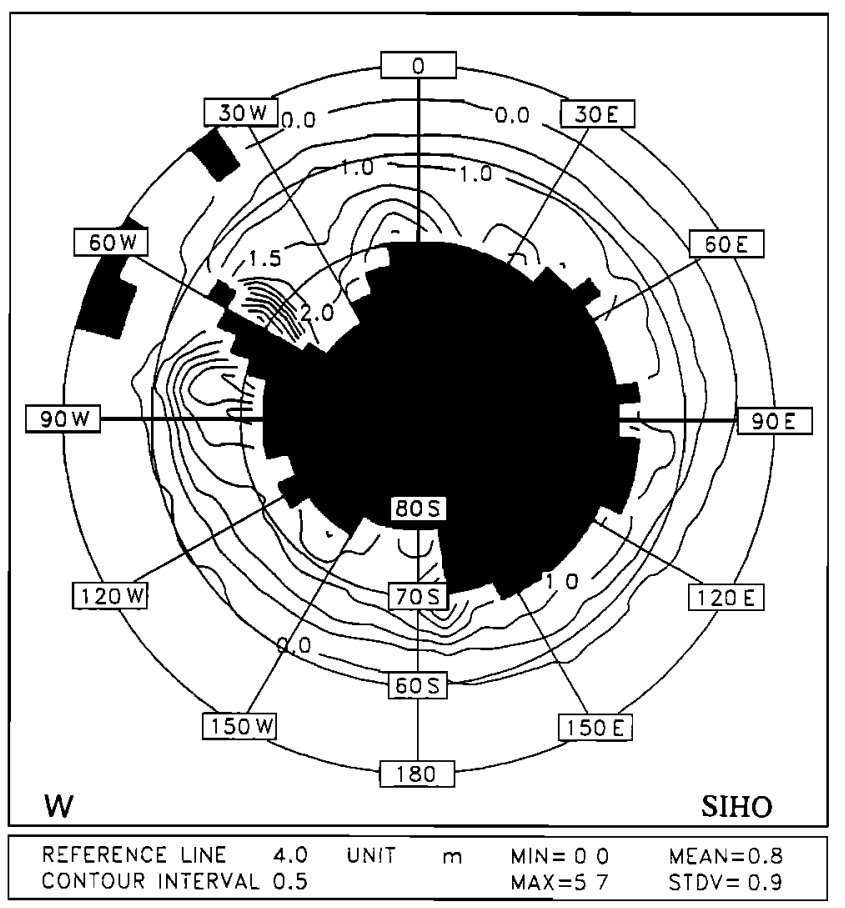

Figure 3. SIHO sea ice simulation with centered differences in space for ice advection; otherwise as Figure 1 for W.

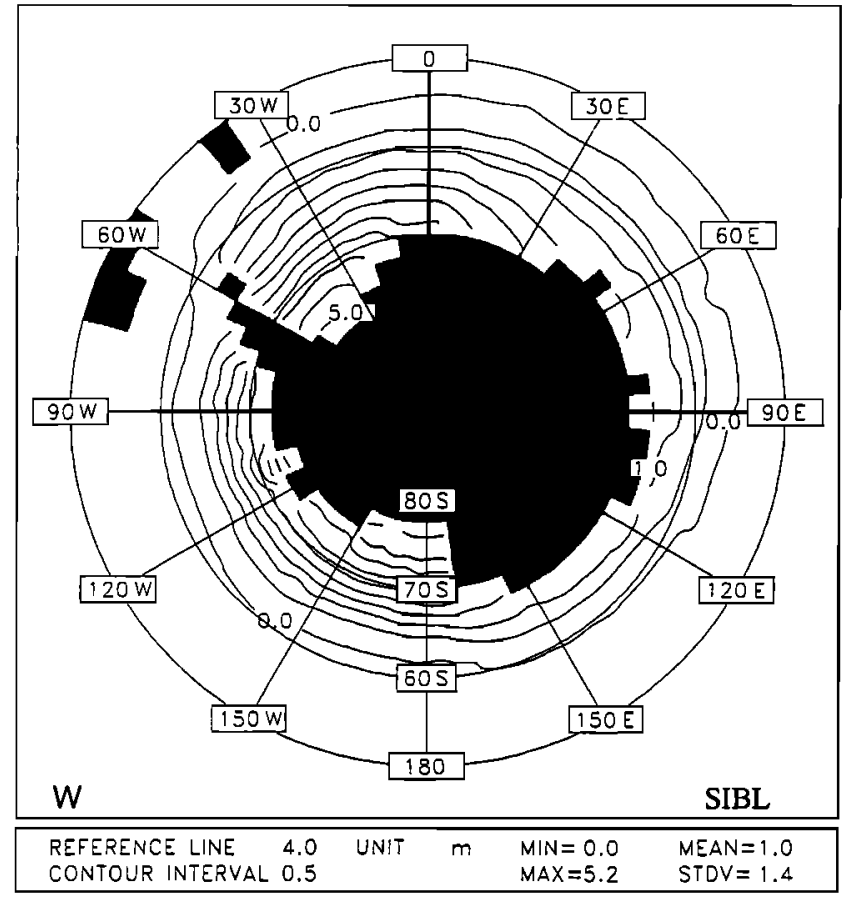

Figure 4. Winter ice thickness distribution simulated with SIBL with zero dynamic forcing; otherwise as Figure 1.

[1979] for these terms, the results are more similar to the corresponding SIBL simulation (Figure 5b), at least with respect to mean ice thickness. The alternative flux-form formulation of the sea ice momentum equation (equations (B1)(B3)) and the latitudinal-dependent diffusion term in OPYC were found to have only a minor impact on the results. The remaining differences are presumably due to the fully implicit numerical treatment of the momentum equation (Appendix B).

Substantial deviations in terms of ice thickness distribution occur with the corresponding SIHO simulation (Figure 4 versus Figure 6a). This was analyzed to be due to a different numerical treatment of the off-diagonal terms of the strain rate tensor, leading to a residual ice drift of up to $6 \mathrm{~cm} / \mathrm{s}$. This yields a dynamically controlled ice thickness distribution as opposed to a more zonal ice thickness distribution to be expected from a simulation dominated by thermodynamics. Using an implicit numerical formulation for the symmetric second-order derivatives of the terms mentioned above, the residual ice drift is reduced to less than $1 \mathrm{~cm} / \mathrm{s}$ as in the SIBL and OPYC simulations, and the results yield the expected zonal ice thickness distribution (Figure 6b). This experiment reflects the high sensibility of the balance between the individual components of the internal ice stress term in the case of zero external forcing.

The latter experiments were mainly demonstrated for academic purposes; for real situations the differences are negligible. Specifically, viscous creep, situations of which were shown here, is part of the viscous-plastic model where it was introduced in order to avoid arbitrarily large viscosities at very small strain rates [Hibler, 1979; Gray and Killworth, 1995].

\subsection{Thermodynamic Performance}

In order to investigate the behavior of the individual thermodynamic formulations the original OPYC and HOPE sea ice models are compared with the SIOP and SIHO versions. Figure 7 shows the individual performances, again in terms of 

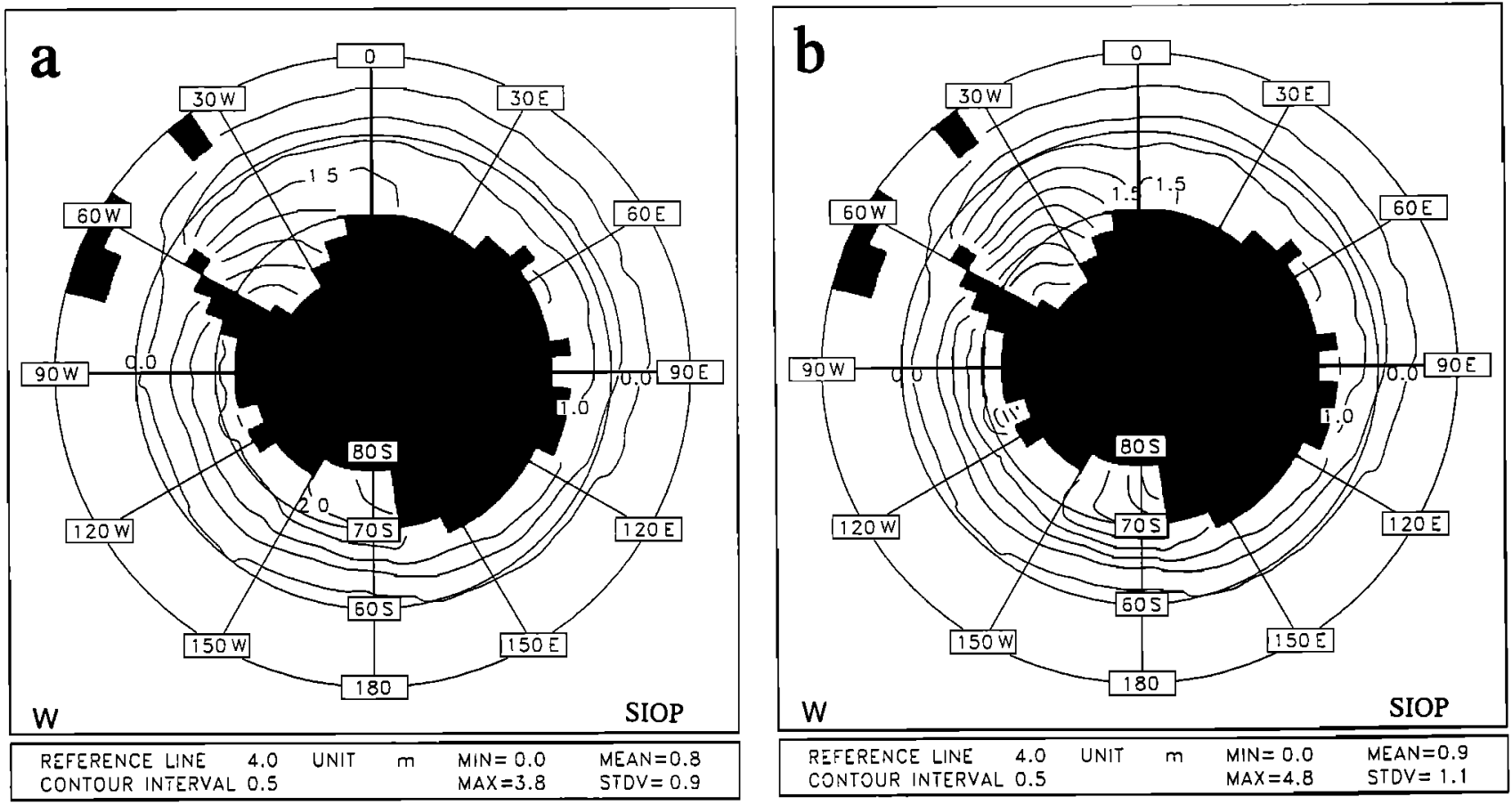

Figure 5. SIOP simulations (a) with original dynamic formulation and (b) with viscosities described as in SIBL; otherwise, as Figure 4.

the seasonal ice thickness patterns. Since SIBL thermodynamics are employed to produce Figure 2 (the SIOP and SIHO versions), any differences between Figures 7 and 2 can directly be related to differences in the thermodynamic formulations. (Alternatively, we could have followed the strategy to combine
SIBL dynamics with OPYC and HOPE sea ice thermodynamics, and make the comparison with Figure 1.) Generally, while the pattern of the OPYC simulation (Figure 7a) is similar to the SIOP simulation (Figure 2a), the ice thicknesses are significantly higher, together with the summer ice extent being
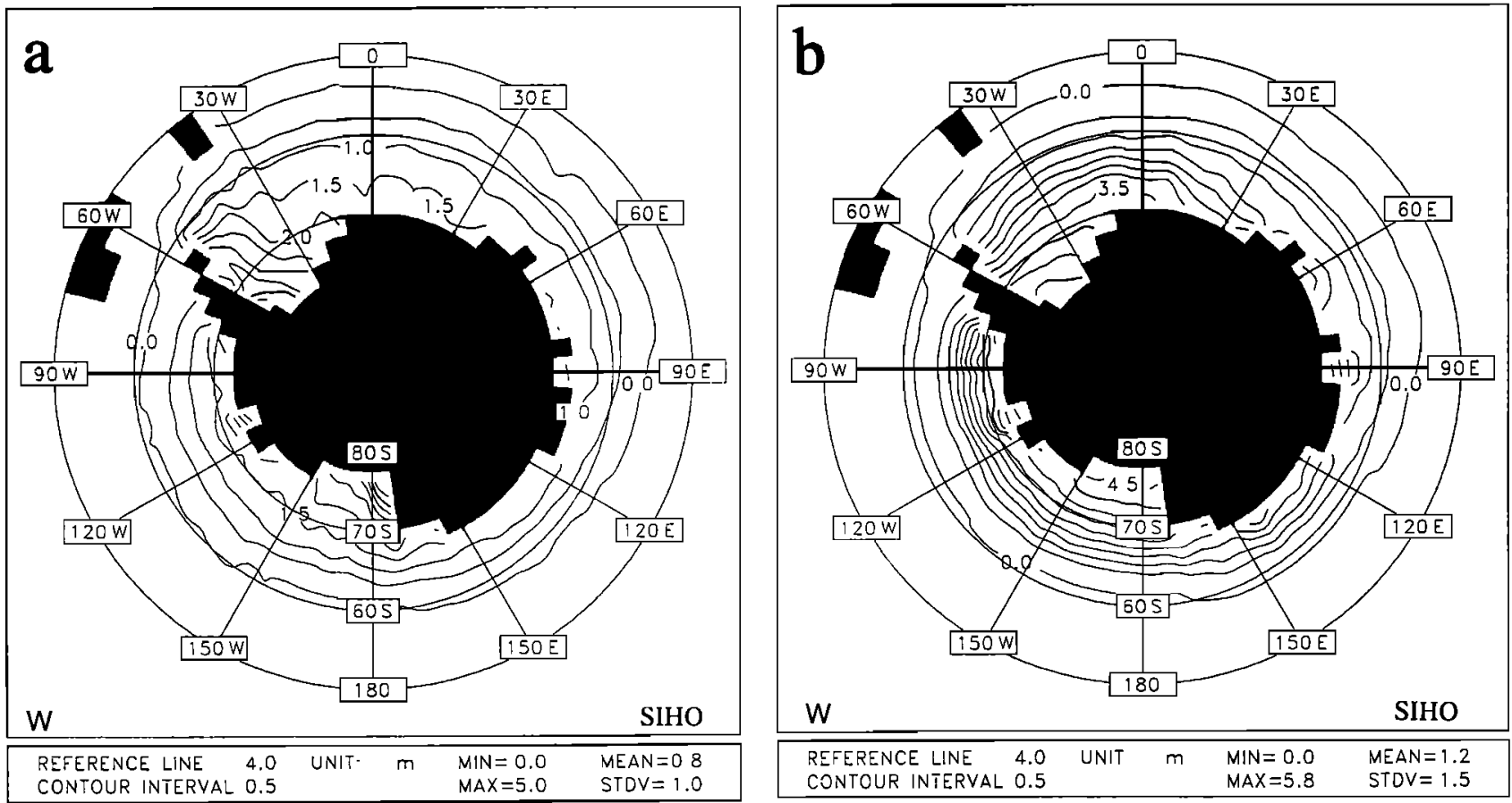

Figure 6. SIHO simulations (a) with original dynamic formulation and (b) with same numerical treatment of symmetric second-order derivatives as in SIBL; otherwise as Figure 4. 

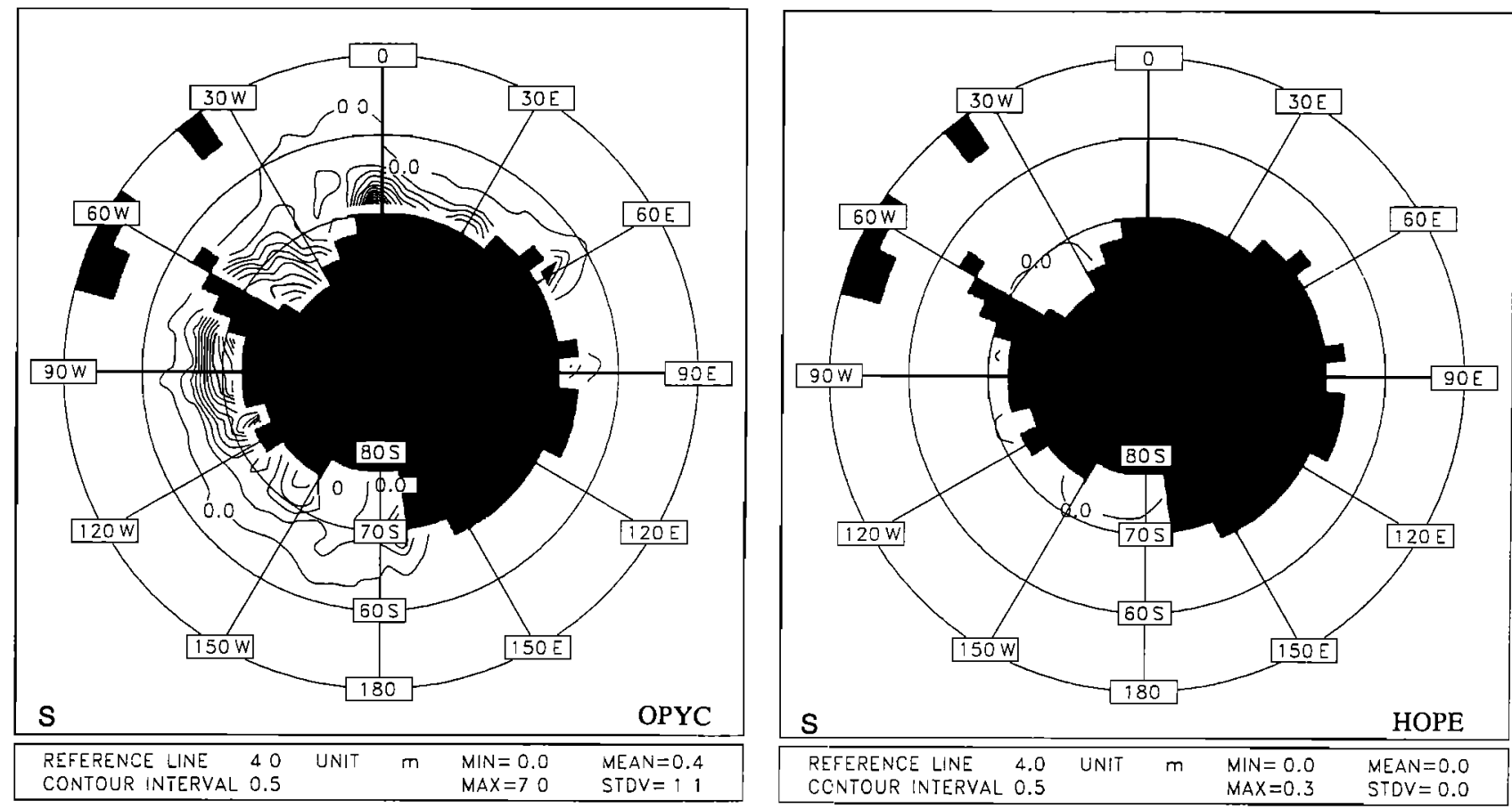

a

b
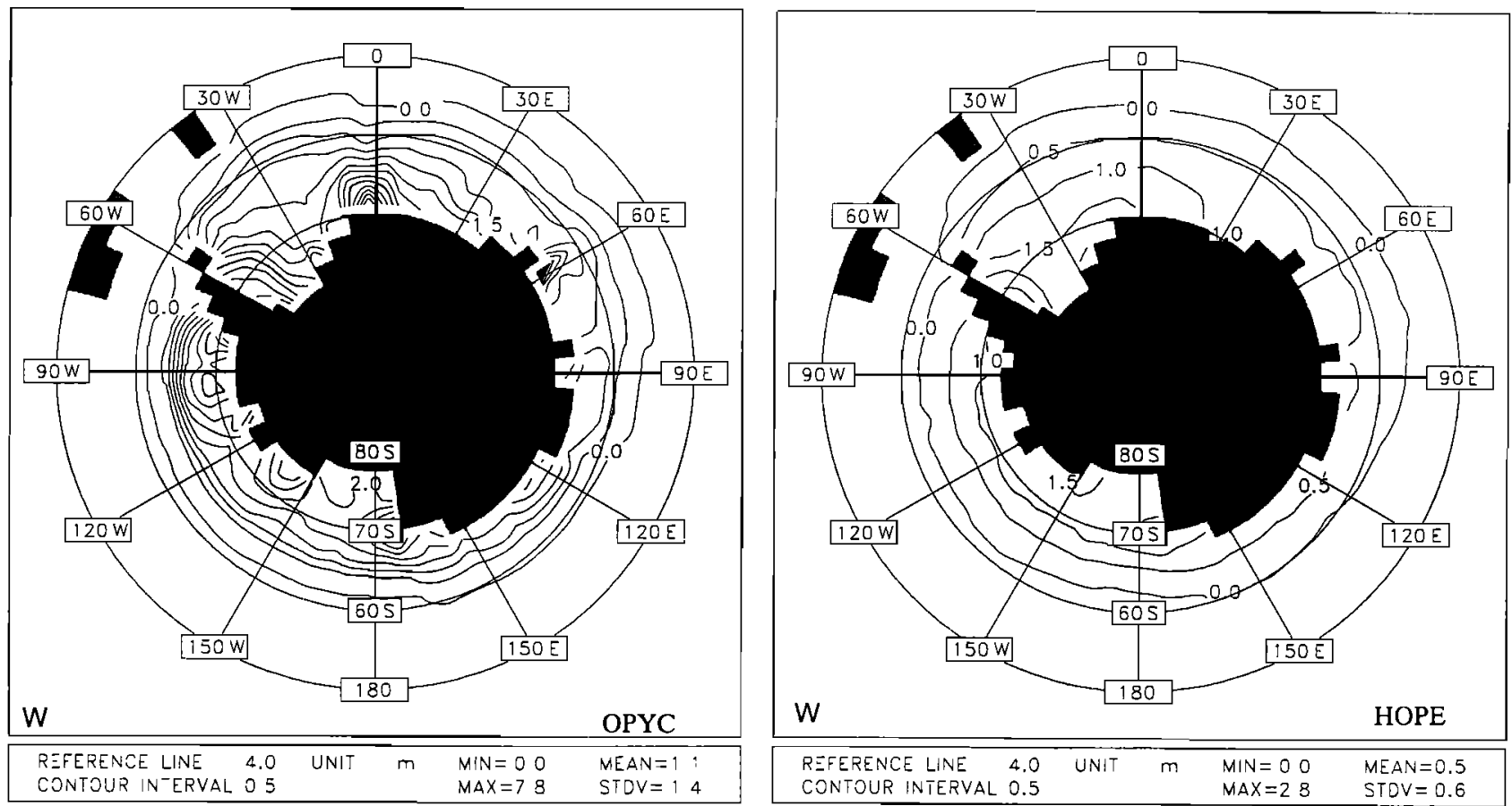

Figure 7. Results with original (a) OPYC and (b) HOPE sea-ice models; otherwise as Fig. 2.

overestimated. The HOPE pattern, on the other hand, reveals much lower ice thicknesses and an underestimated summer ice extent relative to $\mathrm{SIHO}$.

A comparison of the OPYC sea ice model performance versus SIOP is also given in terms of seasonal cycles of ice extent (Figure 8a) and ice volume (Figure 8b), with the unmarked curves representing the SIOP result, and the soliddotted curve the corresponding OPYC result. OPYC turns out to produce a $6 \times 10^{6} \mathrm{~km}^{2}$ smaller seasonal amplitude in ice extent and about $5 \times 10^{3} \mathrm{~km}^{3}$ more ice volume. It should be mentioned that the empirical parameters which correspond to the formulation of Hibler [1979], i.e., $P^{*}, C^{*}, h^{*}$, and $\dot{\varepsilon}_{0}$ (equations (B4)-(B8)), are given the original values in all model experiments. The additional coefficient $C_{\text {frez }}$ in OPYC (equation (B8)) is considered to be 1 . All other additional parameters were adopted from the original OPYC code [Oberhuber, 1993b].

The differences between OPYC and SIOP, mostly occurring during the summer season (about twice the magnitude of the corresponding SIOP values), suggest deviations in the treat- 

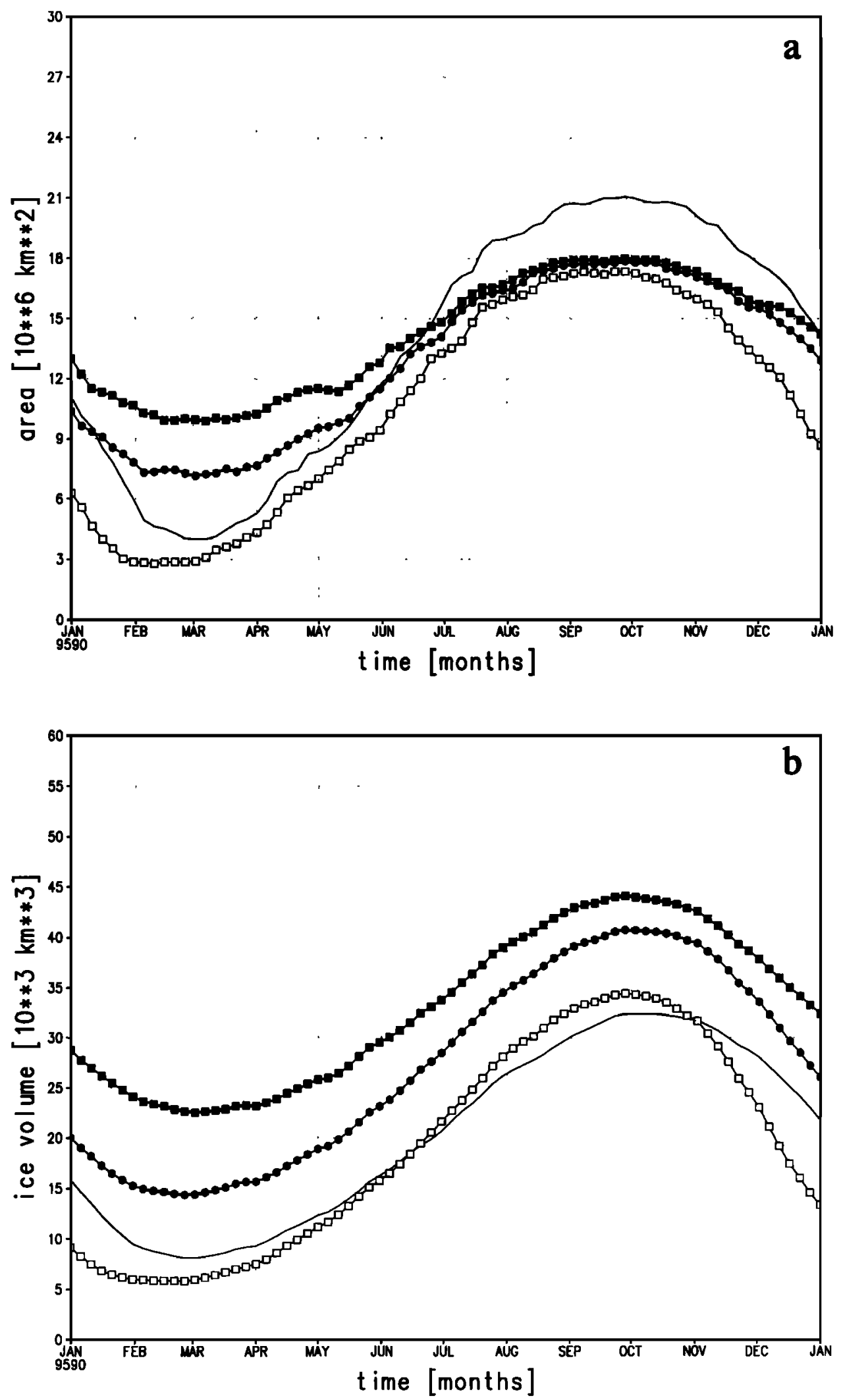

Figure 8. Seasonal cycles of (a) ice extent and (b) ice volume as simulated with the OPYC sea ice model with the original cloudiness factor after Reed [1977] (solid-dotted curves), with the cloudiness factor used in SIBL after Laevastu [1960] (open-squared curves), with the ice albedo used in SIBL (solid-squared curves) and as simulated with SIOP (unmarked curves). 
ment of the shortwave radiation and the albedo. Analyzing the treatment of the solar radiation in OPYC, it was found that the decisive component leading to the above differences is the cloudiness factor, described in OPYC as

$$
1-0.62 N_{\mathrm{cl}}+0.0019 z_{\mathrm{Omax}}
$$

where $N_{\mathrm{cl}}$ is the cloud coverage and $z_{\text {Omax }}$ is the solar altitude at culmination, following Reed [1977]. The corresponding factor in SIBL is given by

$$
1-0.6 N_{\mathrm{cl}}^{3}
$$

following Laevastu [1960]. While (1) is essentially designed to modify the solar radiation over the oceans at mid and low latitudes, the older empirical formula seems to be more adequate in high latitudes [e.g., Parkinson and Washington, 1979]. However, the cloudiness factor seems to be rather ambiguous [Maykut, 1986]. Recent comparisons of different cloudiness formulations suggest that Reed's [1977] formula delivers the most reasonable results [Haapala et al., 1993], at least as measured at one location at $\varphi=60^{\circ} \mathrm{N}$. More research is underway to provide more consistent radiative heat flux schemes [e.g., Curry et al., 1993]. It is beyond the scope of the present study to assess any of these parameterizations. The effect of such heat flux differences is nevertheless nonnegligible, reaching up to $40 \mathrm{~W} / \mathrm{m}^{2}$ in summertime in the present simulations.

The impact of such differences on the sea ice simulations is illustrated with the other two curves in Figure 8. The opensquared curves represent results achieved with the OPYC sea ice model provided with the Laevastu [1960] correction. The OPYC performance with this cloudiness factor yields a much closer agreement to the corresponding results with SIOP, at least in terms of a reduced ice extent in summer and a significantly smaller ice volume.

In order to partly compensate for the lower incoming shortwave radiation, an "effective ice albedo" is used in the original OPYC version, which in summer effectively leads to an ice albedo of only half its common value of about 0.6. Such low values are usually assigned for melt ponds on the ice, a feature which is, however, observed only on Arctic sea ice during July and August [e.g., Andreas and Ackley, 1982; Barry et al., 1993; Allison et al., 1993]. Thus the improvement of the results due to the introduction of the effective ice albedo (as illustrated in Figure 8 with the solid-squared lines) should rather be considered a quantity compensating for discrepancies in the shortwave radiation balance.

Allowing for heat storage effects in the OPYC sea ice code has only a minor impact on the results, presumably due to the rather thin ice occurring in the Southern Ocean. Phase shifts of up to two weeks due to the introduction of heat capacity were detected for Arctic simulations [Holland et al., 1993]. Interestingly, the winter maximum in ice volume is achieved roughly 2 weeks earlier with the OPYC simulations versus SIOP.

A more sensitive parameter in the OPYC sea ice model is $C_{\text {frez }}$ in equation (B8). Setting $C_{\text {frez }}=3$ (as proposed in the original OPYC version) yields a much better agreement of the seasonal ice extent and ice thickness distribution with those of SIOP. As described in Appendix B, a higher $C_{\text {frez }}$ value roughly compensates for the fact that a mean ice growth rate is used to describe the rate of lead closing (equation (B8)), instead of a new-ice growth rate, as used in SIBL following Hibler [1979]. In order to demonstrate this impact more effectively, experiments have been carried out where ice dynamics have been neglected altogether. Figure 9 shows the seasonal cycles of ice extent (Figure 9a) and ice volume (Figure 9b) from such pure thermodynamic simulations for SIBL (unmarked curves) and for the corresponding OPYC sea ice simulations (solidmarked curves). As expected for the Southern Ocean, such simulations suppress the seasonal variations (unmarked curves in Figure 8 versus Figure 9). The solid-dotted curves in Figure 9 represent thermodynamic OPYC simulations with $C_{\text {frez }}=1$. The solid-squared curves, on the other hand, are achieved with $C_{\text {frez }}=3$.

The winter maxima in the SIBL and the OPYC simulations are comparable for the case with $C_{\text {frez }}=1$. However, substantial deviations occur during spring and summer. Surprisingly, these deviations are opposite to the corresponding dynamicthermodynamic performance (Figure 8a, unmarked curve versus solid-dotted curve). This is explained by the fact that most of the ice melt is provided through openings within the ice pack, that is, by warming of the oceanic mixed layer and subsequent melting of the ice. This process is strongly determined by the amount of incoming solar radiation and is thus highly affected by the varying cloudiness correction. The compensating lower ice albedo in OPYC, on the other hand, influences only the ice-covered part of a grid cell. Leads are mostly formed dynamically due to wind variability and are thus not adequately represented in a pure thermodynamic experiment. Therefore the lower albedo leads to an effective reduction in summer ice extent. Mixed-layer warming between the ice pack, on the other hand, is only active at the marginal ice zone, being determined by equation (B8).

For both thermodynamic OPYC simulations there exists an overestimation of ice thickness in the thicker ranges of the ice pack versus the corresponding SIBL simulation. This is primarily related to differences in the snow thicknesses, the snow volume of the OPYC simulation being on average some $20 \%$ lower than in the SIBL simulation. This is mainly due to the incorporation of snow aging in the OPYC sea ice model which, as mentioned in Appendix B, is of the same order of magnitude as the precipitation rate. It reduces the overall snow cover by about $60 \%$ in the thermodynamic experiment. The smaller snow thicknesses (occasionally approaching zero) significantly reduce the snow's insulating effect, leading to stronger growth rates.

Similar experiments with the initial HOPE sea ice model version yield much smaller ice thicknesses (Figure 7b). The HOPE sea ice thermodynamics are principally different from SIBL (and OPYC) with respect to the treatment of the surface heat fluxes, as explained in Appendix C. Furthermore, in the Drijfhout et al. [1996] HOPE version, which is the basis for the present investigation, a solar radiational heat flux term was introduced to modify the heat balance over sea ice consistently to the treatment of the ice-free ocean of their global OGCM. This turned out to be the main reason for the discrepancies between Figures $7 b$ and $2 b$.

Neglecting the direct impact of solar radiation over the icecovered part leads to a substantial increase in ice thickness and to an overall ice thickness distribution which is in relative good agreement with Figure $2 b$ (not shown). This similarity is surprising and suggests that most of the information from the atmosphere needed for sea ice thermodynamics is contained in the near-surface air temperature. The main effect of solar radiation in enhancing the seasonal cycle is represented by the heating through leads, i.e., indirectly by warming the upper ocean, which then provides the heat to melt the ice from below. 

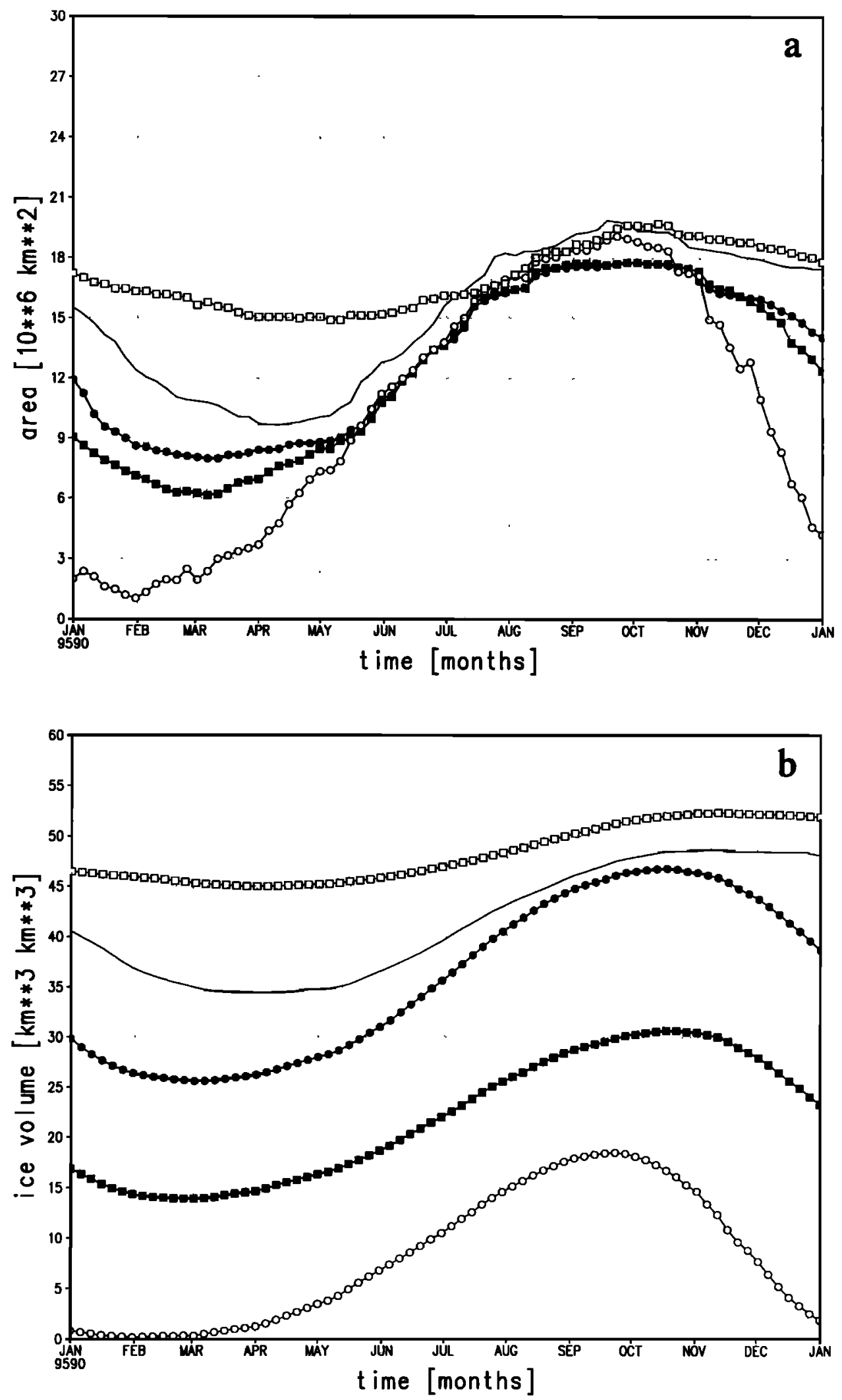

Figure 9. Thermodynamic sea ice simulations of (a) ice extent and (b) ice volume: SIBL (unmarked curves), OPYC (solid-marked curves) with original configuration (solid-dotted curves) and with $C_{\text {frez }}=3$ (solidsquared curves), and HOPE (open-marked curves) with original configuration (open-dotted curves) and with effect of solar radiation over ice-covered part neglected (open-squared curves); otherwise as Figure 8. 
Thus the assumption that the upper temperature forcing in (C1) is determined by the near-surface air temperature rather than the surface (skin) temperature appears to first-order reasonable. It must be ensured, however, that this pseudo surface temperature is treated as representing the net effect of the various fluxes at the surface and should not be modified by an additional flux at a later stage.

This is further elaborated in thermodynamic simulations with the HOPE sea ice model (Figure 9, open-marked curves). For the original configuration (open-dotted curves), a large seasonal cycle of ice extent is achieved. Ice volume is much lower than in all other simulations, approaching zero in summertime. Additionally, the time of the lower culmination of ice extent and ice volume are encountered 2-3 months earlier than in the corresponding SIBL simulation, more closely following the southern hemisphere summer solstice. The neglect of the direct impact of solar radiation on ice (open-squared lines), on the other hand, reduces the amplitude of the seasonal cycles substantially and increases the overall magnitude of ice volume to even higher values than achieved with SIBL. Additionally, this shifts the times of maxima and minima to those of the thermodynamic SIBL simulation.

The latter experiments illustrate the previously mentioned exaggerated sensitivity with respect to the solar radiation term. The pure thermodynamic simulation with the direct impact of the solar radiation on ice included yields a pronounced seasonal cycle of ice extent in the range achieved with a simulation including ice dynamics. This expresses the inappropriateness of this term. The effect is similar to imposing a constant heat flux, e.g., from the ocean, where "reasonable" results in terms of the seasonal cycle of ice extent can also be achieved without dynamics [Stössel et al., 1990].

The overestimated ice volume and the severly overestimated summer ice extent in the modified thermodynamic simulation (Figure 9b, open-squared curves), though still more reasonable than the result of the unmodified thermodynamic simulation, is entirely due to the crude assumption that the imposed air temperature is representative for a (heat flux balanced) surface temperature. This shows that while this assumption is not so crucial in a dynamic-thermodynamic simulation (which is generally less sensitive to perturbations than a pure thermodynamic simulation), the impact can be decisive in a thermodynamically controlled environment.

\section{Impact on the Upper Ocean Boundary Condition}

The strongest impact of sea ice on the ocean occurs due to the salinity difference between sea ice and ocean [e.g., MaierReimer, 1993; Olbers and Wübber, 1991]. This is associated with substantial brine release wherever sea ice is formed and freshwater input wherever it is melted. The most illustrative quantity related to these features is the integral over one seasonal cycle of local freezing minus melting. This net freezing rate is shown in Figure 10 for the SIBL model and the original OPYC and HOPE sea ice models, representing the integral over the final year of numerical integration. While Figure 10a corresponds to Figure 1, Figures $10 \mathrm{~b}$ and $10 \mathrm{c}$ correspond to Figures $7 \mathrm{a}$ and $7 \mathrm{~b}$.

Although the ice thickness patterns of OPYC and HOPE deviate in both directions of the corresponding SIBL result, the freezing rate patterns of OPYC and HOPE are more similar to each other than to the corresponding SIBL pattern.
The latter shows a much more pronounced dynamical character of Southern Ocean sea ice. Since the dynamic features of the OPYC and HOPE sea ice components were analyzed to be rather similar under usual forcing conditions, the main reasons for the differences in the net freezing rates are due to the different thermodynamic formulations as investigated in section 3.2. The discrepancy to the OPYC result can be explained by the overall larger thicknesses in the OPYC simulation (Figure $7 \mathrm{a}$ ), which tend to reduce ice growth. Owing to the strong warming effect of the extra solar radiation term in HOPE, this model produces less ice. Part of the discrepancies between all three models is associated with the treatment of new-ice growth. This will be addressed in section 6 .

The point to be made here is that while the overall pattern of ice formation along the coast of Antarctica and in most of the areas in the Weddell and Ross Seas is consistent, there are substantial differences in the magnitudes of the surface freshwater forcing depending on which sea ice model is used. Values up to a few meters of ice thickness equivalent surplus or deficit in the freshwater balance is of the same size as typical extreme values for imposed precipitation-minus-evaporation (P-E) fluxes for an OGCM. We may remind that the models investigated here include state-of-the-art sea ice dynamics, none of which, to the knowledge of the authors, is accounted for in any other global OGCM. Neglecting essential features of sea ice dynamics (as, e.g., in the GFDL and LSG OGCM) may lead to even larger differences in the net freezing patterns and thus different thermohaline forcing conditions. This will be addressed in section 5. An example of the significance of the latter effect was presented by Olbers and Wübber [1991], who investigated the impact of the freezing-minus-melting pattern on the momentum balance of the ACC. The ACC increased by $45 \mathrm{~Sv}$ in response to sea ice induced salt flux produced by a dynamic-thermodynamic sea ice model versus no such effect, i.e., assuming zero net freezing throughout the seasonal cycle.

\section{Impact of Wind Forcing}

The most widely used global OGCMs are the GFDL model [e.g., Semtner and Chervin, 1992; Manabe et al., 1992; Washington et al., 1994] and the LSG model [e.g., Mikolajewicz et al., 1990; Cubasch et al., 1992; Pierce et al., 1995]. In those models the brine rejection effect of sea ice is considered by employing an ice growth formula to account for the conductive heat flux through the ice layer (except for the solar radiation term discussed in section 3.2, the thermodynamic part of the LSG sea ice model is the same as in the original HOPE version described in Appendix C). Furthermore, ice is advected with the ocean current of the uppermost layer(s). In order to avoid excessive dynamic ice pile-up, the ice is assumed to be stagnant beyond a specified threshold ice thickness in the GFDL model [Bryan, 1969], while a simple viscous rheology is employed in the LSG model [Maier-Reimer et al., 1993].

In order to estimate the effect of neglecting direct wind forcing of the ice, we performed three experiments with the SIBL model. In all these experiments we assume zero stress between atmosphere and ice. The resulting seasonal cycles are shown in Figure 11 in comparison with the standard winddriven ice run (unmarked curves). In the first experiment we assumed a stagnant ocean throughout the simulation (soliddotted curves). In the second experiment, geostrophic ocean currents, based on the upper $1000 \mathrm{~m}$ climatological density structure according to Gordon et al. [1978], are employed as 


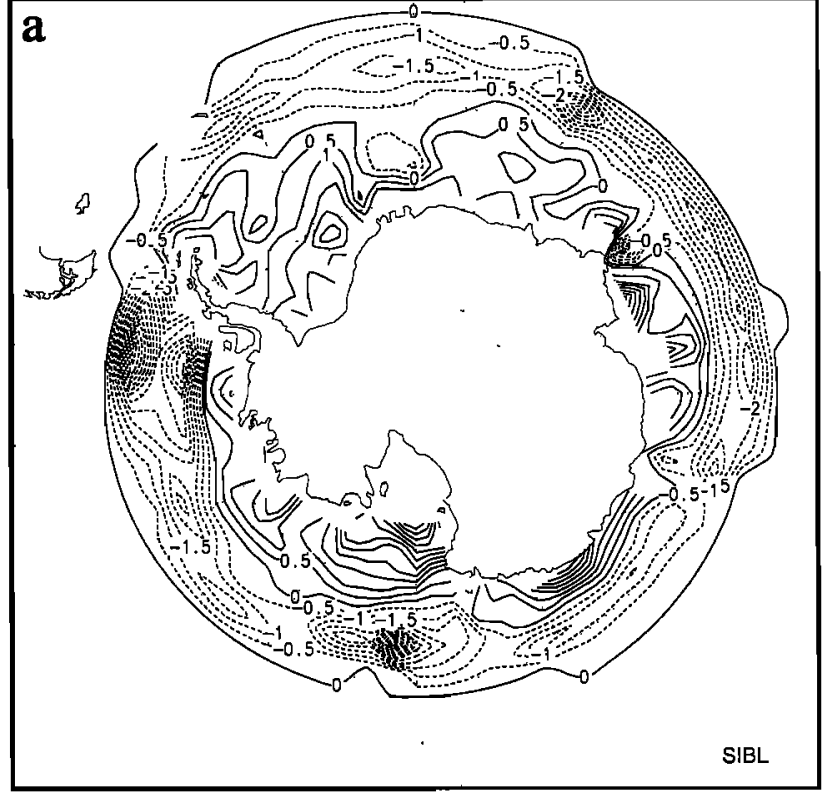

Contouring: -6.5 to 5.5 interval $0.5 \mathrm{~m}$

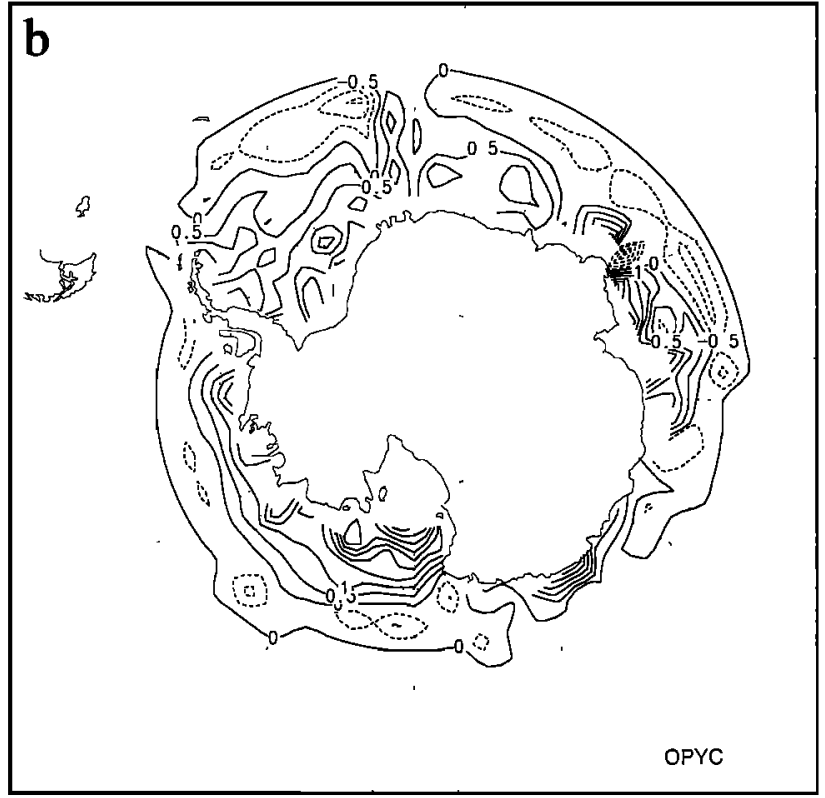

Contouring: -2.5 to 4.5 interval $0.5 \mathrm{~m}$

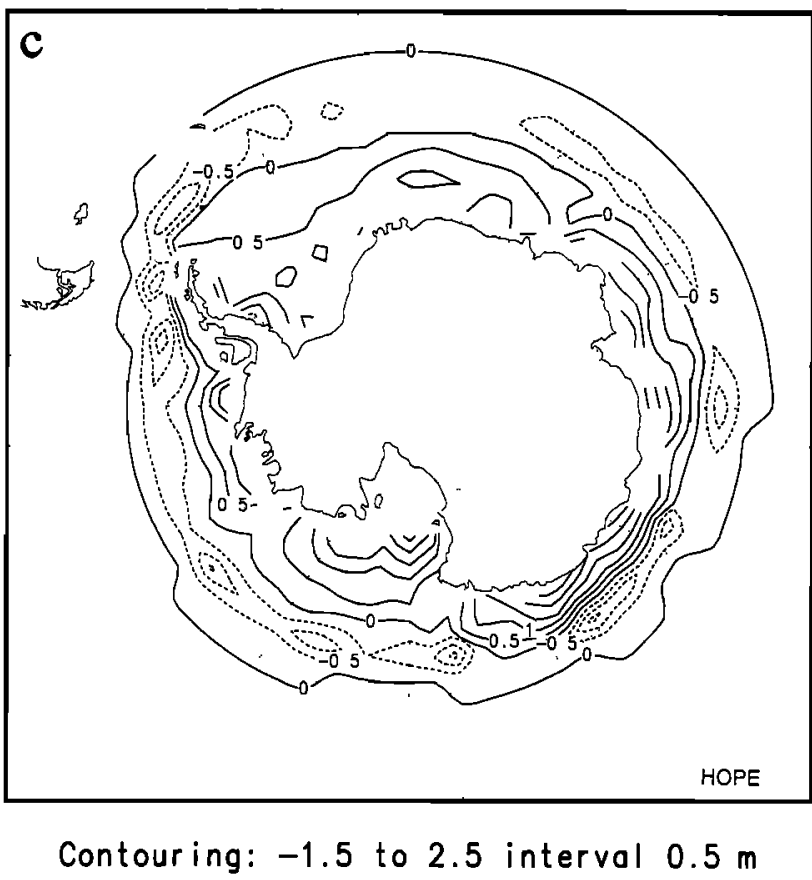

Figure 10. Spatial pattern of annual net freezing rate simulated with (a) SIBL and the original sea ice models of (b) OPYC and (c) HOPE.

surface ocean current (open-squared curves). Finally, we employed the total ocean currents (barotropic plus baroclinic component) of a full HOPE OGCM integration to drive the SIBL model dynamically (the "indirectly wind-driven experiment"). The OGCM integration was forced in the Southern Ocean with the same daily wind forcing as used in all the stand-alone sea ice simulations of this study. In that OGCM run, sea ice drift is not assumed to affect the Ekman current; instead, the momentum input from the atmosphere is directly provided by the wind stress, regardless of the existence of any sea ice. This is consistent with the treatment in most global ocean models with a dynamic sea ice component [e.g., Manabe et al., 1992; Cubasch et al., 1992], as well as in some regional sea ice-ocean models [e.g., Hibler and Bryan, 1987].

The ice extent turns out to be rather similar in all experiments, except for the summer months. The ice volume, on the other hand, is substantially larger in the ocean-driven sea ice experiments than in the directly wind-driven experiment. The reduction in the amplitude of the seasonal cycles already gives a hint that the sea ice in the sensitivity experiments does have a deficit in the dynamical balance: with less dynamic activity, Southern Ocean sea ice tends to approach a more thermodynamic pattern, reflected in an increase in summer ice extent and an overall increase in ice volume (see section 3.2 and 

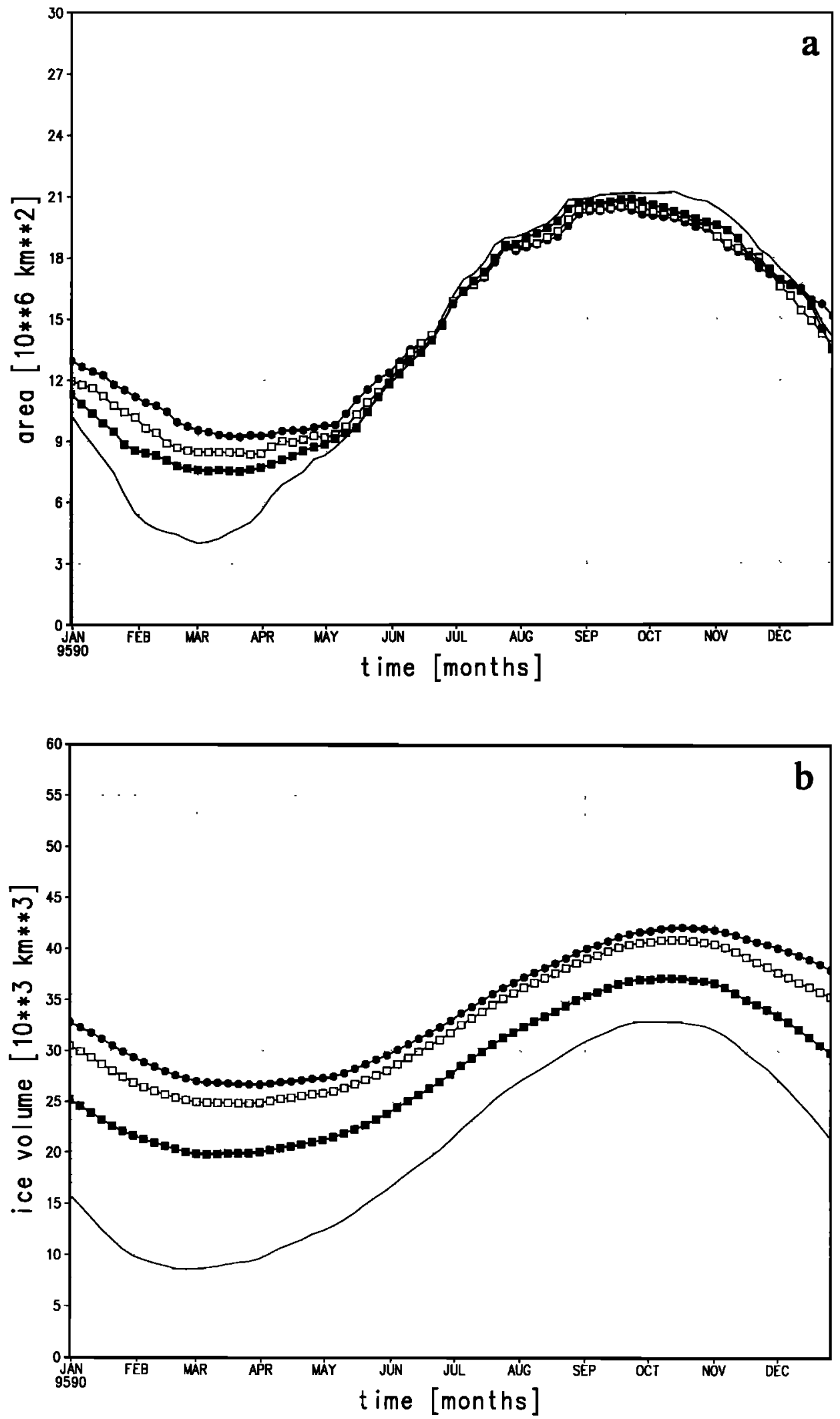

Figure 11. SIBL sensitivity simulations without direct wind forcing: without ocean current forcing (soliddotted curves), with geostrophic current forcing (open-squared curves), and with indirect wind forcing via total ocean currents (solid-squared curves); SIBL simulation with direct wind (and geostrophic current) forcing for reference (unmarked curves); otherwise as Figure 8. 


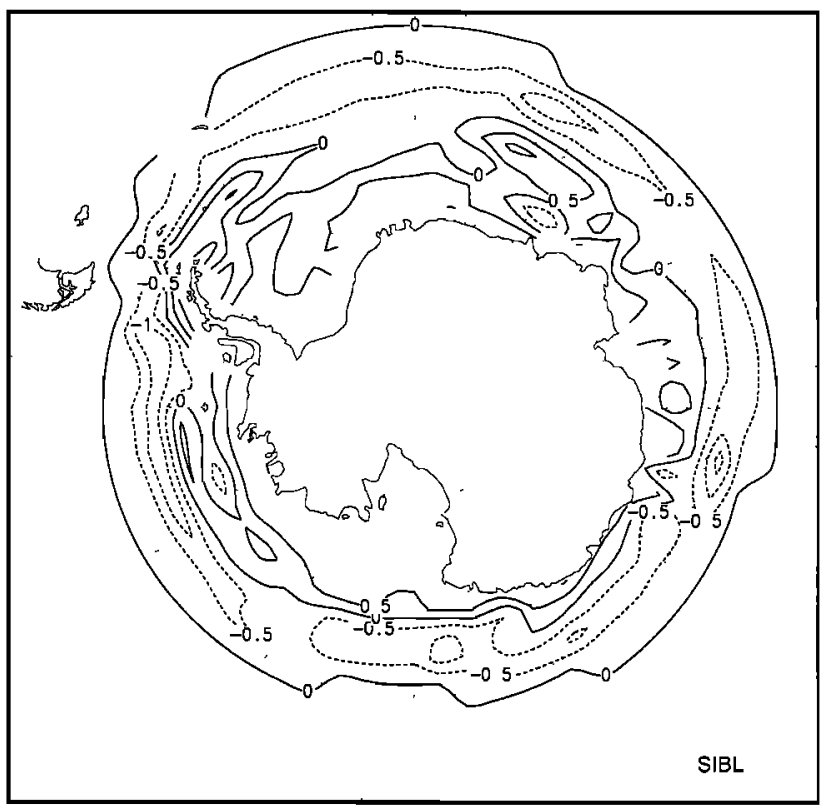

Contouring: -1.5 to 1 interval $0.5 \mathrm{~m}$

Figure 12. SIBL sensitivity simulation with indirect wind forcing via total ocean currents; otherwise as Figure 10a.

Stössel et al. [1990]). Overestimations of Southern Ocean summer ice extent and year-around ice volume are also typical for coupled GCM simulations undertaken, e.g., by Cubasch et al. [1994] using the LSG model and Manabe et al. [1992] using the GFDL model as their respective ocean components.

The close similarity of ice extent for all experiments from May until December suggests that the limiting factor is given by the thermal ambient conditions (polar front [e.g., Whitworth, 1988]). In summer, the dynamic conditions become more decisive, reflected in the gradual improvement from the no-ocean currents, via a geostrophic current, to a fully windand thermohaline-driven current. In thermodynamically weakened ice conditions and regions of predominantly weak currents the wind forcing of the ice provides the driving force to export ice out of the southern regions. Specifically, ice breakup and lower ice concentrations lead to higher mobility, resulting in a positive feedback of enhanced breakup of the ice pack with increasing dynamic forcing (the strongest of which is given by direct wind forcing).

In the wind-driven ice case the $O(1 \mathrm{~m})$ thick ice floes move generally faster than the underlying ocean even if the ocean is entirely wind driven. This has two simple reasons: first, the ocean surface does not instantaneously adjust to the daily fluctuating wind forcing (at least not if ocean model surface currents mirror the horizontal velocity of an $\mathrm{O}(30 \mathrm{~m})$ thick layer). Second, in reality, the (wind-driven) ice usually provides the momentum input to the ocean (i.e., the ice-ocean stress, and not the "wind stress"). In situations of divergent ice motion (when the internal ice stress is zero), i.e., ice drifting "free" with wind and currents, the ice-ocean stress usually provides a retarding force to the ice drift (thereby eventually introducing more momentum into the ocean than the (open ocean) atmosphere-to-ocean wind stress).

An ultimate effect of using crude assumptions of the kind described above can be seen in the annually integrated freezing-minus-melting pattern produced with the indirectly wind- driven sensitivity experiment (Figure 12). A comparison with Figure 10a reveals up to a factor of 4 difference in the magnitudes, while the pattern of the sign of the net freezing rate is roughly the same. This clearly reflects the difference between the indirect dynamic forcing of sea ice by smoothed upper ocean currents versus a direct dynamic forcing by the daily wind field. The crucial role of the net freezing rate was discussed in section 4.

\section{New-Ice Formation}

Another crucial sensitivity is associated with the treatment of new-ice formation in partially ice-covered grid cells, especially the way new-ice formation acts on the grid-cell-averaged ice thickness growth and on the rate of lead closing. Figure 13 shows the impact of three different assumptions used in comparison to the standard formulation in SIBL (i.e., the empirical formulation proposed by Hibler [1979]). In the original HOPE sea ice model, new-ice formation is accounted for according to equation (C3) with (C4). However, this is only applied when there is no sea ice in a grid cell initially. Thus, as elaborated in Appendix C, there is no direct new-ice (thickness) growth in partially ice-covered grid cells. Assuming this without further consideration in the SIBL model yields the solid-dotted curves in Figure 13. It demonstrates that new-ice growth in partiallycovered grid cells is the crucial part in determining ice growth.

The original HOPE sea ice model nevertheless still produces a reasonable seasonal amplitude (Figure $7 b$ ). This is due to the fact that the lead-closing rate in the HOPE sea ice model essentially depends on the atmosphere-to-ocean temperature difference (equation (C5)). Though this does not reflect the overall heat balance over a lead, it reflects the first-order effect of a sensible heat flux which is the dominant term in the heat balance over a lead during most of the year. It is physically more realistic than the corresponding formulation in the OPYC model, where the lead-closing rate is assumed to be a function of the growth rate of existing ice (equation (B8)). Neglecting any new-ice growth in partially covered cells, as in our first experiment, but using equation (C5) in SIBL yields the open-squared curves in Figure 13. It can be seen that the lead-closing formulation has a dramatic impact on the results, in this case leading to a considerable improvement. Nevertheless, winter ice volume is substantially less, which is entirely due to the missing new-ice thickness growth.

If we neglect new-ice growth in SIBL only in the ice thickness growth part, keeping the lead-closing rate the same as in the original SIBL formulation (i.e., as a function of the pseudo new-ice thickness growth rate resulting from a comprehensive heat budget), the solid-squared curves in Figure 13 are obtained. This shows that the lead-closing part contributes about $80 \%$ to the integrated ice coverage and about $60 \%$ to the integrated ice thickness.

\section{Summary and Conclusions}

The intention of this study was to investigate the sea ice component of two global OGCMs (OPYC and HOPE), both used for coupled ocean-atmosphere GCM climate studies, and to relate the results to general aspects of representing sea ice in a global-scale framework. The choice of the OGCMs was motivated by the fact that these particular models are to the knowledge of the authors the only one's employing state-ofthe-art sea ice dynamics appropriate for GCM-scale simula- 

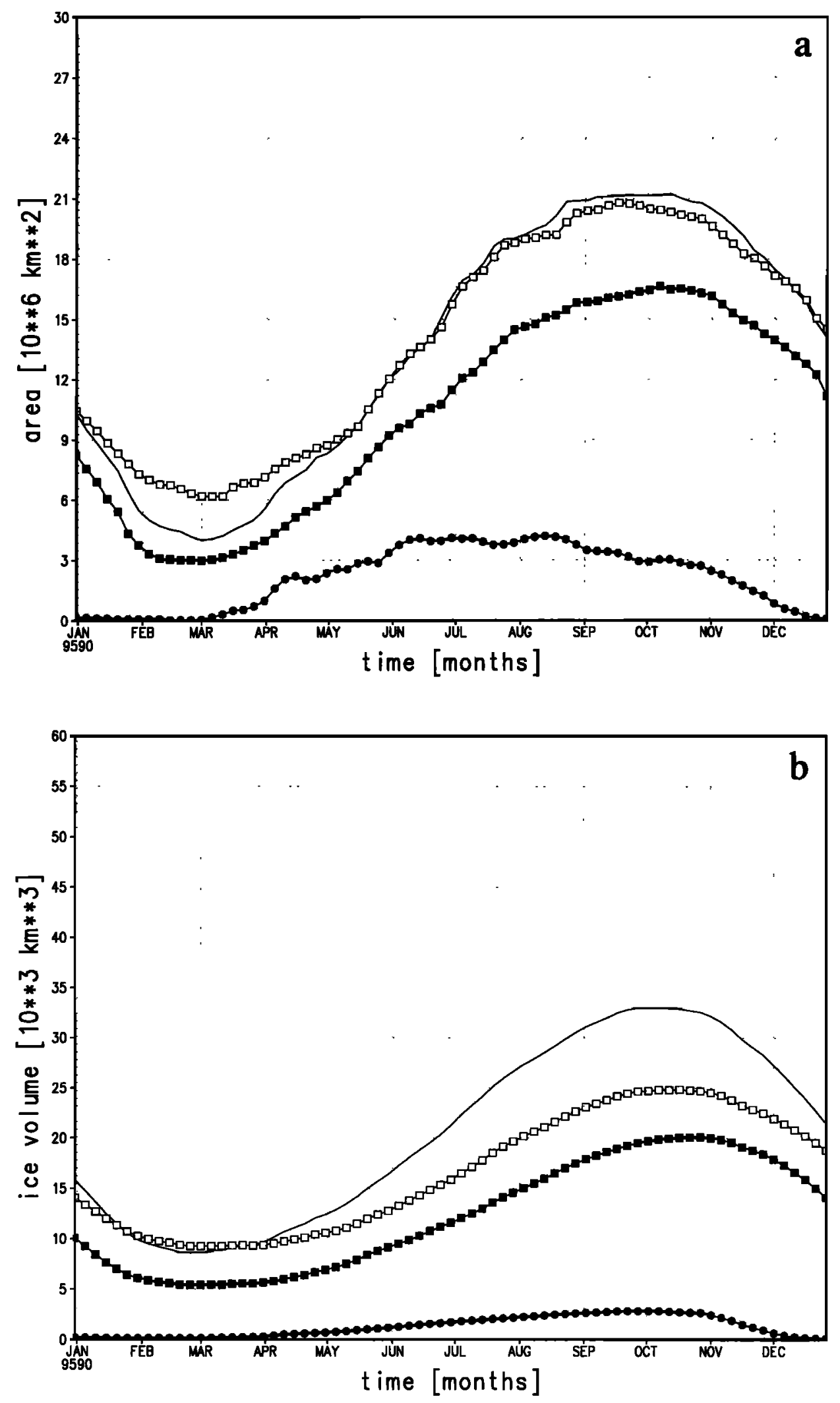

Figure 13. SIBL sensitivity simulations without explicit new-ice formation in partially ice-covered grid cells: neglecting new-ice growth in partially ice-covered cells altogether (solid-dotted curves), adopting equation (C5) for the lead-closing rate (open-squared curves), and neglecting new-ice thickness growth in partially covered cells only (solid-squared curves); otherwise as Figure 11. 
tions. The performance of a concurrent stand-alone sea ice model (SIBL) was used as a reference to validate the OGCM sea ice models. The SIBL model was verified against observations in earlier studies.

In order to detect the inherent characteristics of the respective OGCM sea ice components, these were extracted from their main code and run under the same "realistic" boundary and forcing conditions as the SIBL model. The analysis of the individual sea ice models was organized in four steps:

1. OPYC and HOPE sea ice dynamics and SIBL thermodynamics were combined into the SIOP and SIHO versions in order to assess the dynamic behavior of each model and to create consistent sea ice model versions for later reimplementation into the respective main codes.

2. The impact of the different thermodynamic treatment was investigated using the initial OPYC and HOPE versions in comparison to SIOP and SIHO. These investigations were continued in a pure thermodynamic mode.

3. The annual net freezing rate of the original OGCM sea ice components was examined as this quantity represents a crucial upper boundary condition for an OGCM.

4. Finally, the SIBL model was modified to examine the impact of two factors often neglected in global GCM modeling: the direct wind forcing of sea ice and the new-ice formation in partially ice-covered grid cells.

With the realistic external conditions the dynamic performances of SIBL and the SIOP and SIHO versions generally agreed, despite some differences in the mathematical and numerical formulations (see Appendices B and C). It shows that the viscous-plastic constitutive law introduced by Hibler [1979] can be used efficiently with different numerical techniques. Differences occurred due to the employment of the highly diffusive upstream scheme in HOPE, regionally leading to exaggerated smoothing of the ice thickness distribution. A more reasonable representation of ridging processes was achieved with a spatial centered differencing scheme employing moderate diffusion to ensure numerical stability.

In (unrealistic) situations of zero wind stress and zero ocean current, substantial discrepancies in the dynamic performances occurred with both OGCM sea ice models. This turned out to originate from subtle differences in the treatment of the internal ice stress term, which were identified in the low strain rate regime. Though academically interesting, these discrepancies are not relevant for GCM-scale climate studies.

The sensitivity studies for investigating the different thermodynamic treatment in the initial OPYC and HOPE sea ice model versions revealed some significant discrepancies. For the OPYC model the differences originate from auxiliary calculations like the determination of the cloudiness factor for solar radiation, the specification of the ice albedo, the reproduction of the effect of melt ponds on ice, the more ad hoc parameterization for the rate of lead closing, and the introduction of a snow aging coefficient.

The main discrepancy of the initial HOPE sea ice model version turned out to be due to the crude assumption concerning the surface heat balance, the neglection of snow, different assumptions for lead closing and opening, and the extra addition of the solar radiation. The first assumption that all external information for the growth of existing ice is given by the ambient air temperature (i.e., using this as the surface temperature) yields results which are comparable to SIBL when run in the dynamic-thermodynamic mode but not in the pure thermodynamic simulation. It is thus recommended to involve the complete surface heat balance and to employ the resulting (balanced) ice surface temperature.

Finally, we employed simplifying assumptions commonly used in global OGCM modeling, namely, the neglect of direct wind forcing of the ice pack and the neglect of authentic new-ice growth in partially ice-covered grid cells. The former led to a $100 \%$ increase in summer ice extent, an overall ice thickness increase (more than $100 \%$ in summer and about $20 \%$ in winter), and a factor of 4 decrease in the freezing-rate maxima (and minima). The new-ice growth experiments revealed significant dependencies on the way the new-ice growth rate itself is formulated, and how it influences the overall ice thickness growth; the most sensitive parameter turned out to be the lead-closing rate. Overall, these experiments showed the inappropriateness of some commonly used assumptions in the formulation and the forcing of an OGCM sea ice component. As shown in terms of the annual net freezing rate, such assumptions can lead to first-order changes of crucial upper ocean boundary conditions, which eventually may feed back on the overall performance of an OGCM.

The SIOP and SIHO versions provide a rather unified description of the sea ice component in the framework of the OPYC and the HOPE OGCM. This is especially advantageous for forced OGCM intercomparisons and for coupled AOGCM simulations [see, e.g., Foster and Brown, 1994]. Assuming that the AGCM provides the ice growth rate (or equivalent conductive heat flux) as a function of the surface (sea ice) characteristics of the previous time step, any thermodynamic sea ice (and snow) changes, together with their impact on the upper ocean heat and salinity budgets can now be treated in one sweep through a standardized (and modular) thermodynamics routine.

This study demonstrates that individual OGCM sea ice components can meanwhile reach the stage of state-of-the-art sea ice models. Optimized numerics adjusted to the respective OGCM code allow for a reasonable computational share. Consistent thermodynamic descriptions are recommended to be used for forced and coupled experiments in order to prevent distorted sensitivities to arise from the highly sensible polar regions of a global GCM.

\section{Appendix A: SIBL Model}

The central element of the SIBL model system is the dynamic-thermodynamic sea ice model of Hibler and Ackley [1983]. It was modified by Owens and Lemke [1990] to include a prognostic snow cover and to provide the option to run the model on a latitude-longitude grid rather than a Cartesian grid. Lemke et al. [1990] introduced the option to couple the sea ice model to an oceanic mixed-layer model. Finally, atmospheric boundary layer processes were provided in order to modify the strength of the atmospheric forcing in response to the instantaneous (modeled) sea ice conditions [Stössel, 1992]. The model system and its numerical treatment are described in detail by Stössel and Owens [1992].

\section{Appendix B: OPYC Sea Ice Model}

The equations and the numerical scheme of the present version of the OPYC OGCM are extensively described by Oberhuber [1993b]. The OPYC sea ice model differs from SIBL through the use of the flux form for the momentum equation, the introduction of an additional diffusion term, and the ne- 
glect of the advection of momentum (for simplicity, we use Cartesian coordinates for this illustration):

$$
\begin{aligned}
\rho \frac{\partial}{\partial t}(\mathbf{v} h)= & \rho \nabla \cdot A \nabla(\mathbf{v} h)-\rho f \mathbf{k} \times(\mathbf{v} h)+\rho g h \nabla H \\
& +\tau_{\mathrm{d}}+\tau_{0}+\mathbf{F}
\end{aligned}
$$

where

$\rho$ sea ice density;

$v$ sea ice velocity;

$h$ mean ice thickness within a grid cell;

$A$ constant diffusion coefficient;

$f$ Coriolis parameter;

k unit vector normal to the surface;

$g$ acceleration due to gravity;

$H$ height of dynamic topography;

$\tau_{\mathrm{a}}$ air/ice stress;

$\tau_{0}$ ice/water stress;

F force due to internal ice stress.

\section{Explicitly}

$$
\begin{aligned}
F_{x}= & \left\{\frac{\partial}{\partial x}\left[\left((\zeta+\eta) \frac{\partial u h}{\partial x}+(\zeta-\eta) \frac{\partial v h}{\partial y}\right) / h-\frac{P}{2}\right]\right. \\
& \left.+\frac{\partial}{\partial y}\left[\eta\left(\frac{\partial u h}{\partial y}+\frac{\partial v h}{\partial x}\right) / h\right]\right\} \\
F_{y}= & \left\{\frac{\partial}{\partial y}\left[\left((\zeta+\eta) \frac{\partial v h}{\partial y}+(\zeta-\eta) \frac{\partial u h}{\partial x}\right) / h-\frac{P}{2}\right]\right. \\
& \left.+\frac{\partial}{\partial x}\left[\eta\left(\frac{\partial u h}{\partial y}+\frac{\partial v h}{\partial x}\right) / h\right]\right\}
\end{aligned}
$$

where

$$
\begin{gathered}
P=P^{*} h \exp \left[-C^{*}(1-N)\right] \\
\zeta=P /\left[2\left(\sqrt{\Delta} / m+\dot{\varepsilon}_{0}\right)\right] \\
\eta=\zeta / e^{2}
\end{gathered}
$$

with

$$
\begin{aligned}
\Delta= & \left\{\left[\left(m \frac{\partial u}{\partial x}\right)^{2}+\left(\frac{\partial v}{\partial y}\right)^{2}\right]\left(e^{2}+1\right)+\left(\frac{\partial u}{\partial y}+m \frac{\partial v}{\partial x}\right)^{2}\right. \\
& \left.+2 m \frac{\partial u \partial v}{\partial x \partial y}\left(e^{2}-1\right)\right\} / e^{2}
\end{aligned}
$$

and

e ratio of compressive to shear strength;

$P^{*} \quad$ empirical ice strength parameter;

$C^{*}$ empirical constant;

$\zeta$ bulk viscosity;

$\eta$ shear viscosity;

$\dot{\varepsilon}_{0}$ maximum viscous creep rate;

$m$ empirical coefficient (= cos (latitude))

The first term on the right-hand side of (B1) represents eddy diffusion. Involving nine grid points for the discretization of the rheological calculations is consistent with the basic governing equations. However, with this form of discretization, B grid wave perturbations may occur. These are suppressed with the additional diffusion term. The commonly used five grid point scheme implicitly includes already (numerical) diffusion of the same order of magnitude.

With respect to the internal ice stress, formal differences compared to the original formulation of Hibler [1979] originate from the use of the spatial derivatives of $u h$ and $v h$ instead of $u$ and $v$ and in the definition of $\Delta$ and $\zeta$ (and $\eta$ ) in which a latitudinal dependent coefficient is introduced. Thus the elliptical yield curve is somewhat different from that described by Hibler [1977]. This was necessary in order to compensate for the dependence of the shear and bulk viscosities on the varying model resolution, especially to cope with the convergence of the latitude-longitude grid at the north pole, a problem discussed in more detail by Holland and Oberhuber [1995].

Differences in the continuity equations arise from a different treatment of the thermodynamic terms and a slightly different calculation of the diffusion terms. The main differences with respect to the thermodynamic terms appear in the continuity equation for ice compactness [Holland et al., 1993]:

$(\partial N / \partial t)_{\mathrm{th}}=(\partial h / \partial t)_{\mathrm{th}}\left(\delta_{j k} C_{\text {frez }} \frac{(1-N)}{h^{*}}+\delta_{l n} C_{\text {melt }} \frac{N}{2 h}\right)$

where $j=k$, if $(\partial h / \partial t)_{\mathrm{th}}>0, l=n$, if $(\partial h / \partial t)_{\mathrm{th}} \leq 0, N$ is ice compactness, ()$_{\text {th }}$ indicates with respect to thermodynamics, $\delta$ is Kronecker delta, $C$ is empirical coefficient, and $h^{*}$ is empirical parameter.

Besides including additional empirical parameters, the leadclosing rate for $(\partial h / \partial t)_{\mathrm{th}}>0$ is made dependent on the overall (grid cell averaged) freezing rate instead of the new-ice production rate as proposed by Hibler [1979], thus leading to a substantial delay of thermodynamic lead closing if $C_{\text {frez }}$ is chosen to be 1 . In order to compensate for this delay, $C_{\text {frez }}$ is generally set $>1$, while $C_{\text {melt }}$ is usually taken as 1 (as in the original Hibler [1979] formulation).

Furthermore, the OPYC thermodynamics do not properly separate the heat budget calculation between the ice-free and ice-covered part but instead determine a grid cell averaged "skin temperature" as

$$
T_{\mathrm{s}}=N T_{\mathrm{sn}, \mathrm{l}}+(1-N) T_{\mathrm{o}}
$$

where $T_{\mathrm{sn}, \mathrm{i}}$ is snow or ice surface temperature, and $T_{\mathrm{o}}$ is sea surface temperature, which is used to derive the overall surface heat flux. This has been refined in a more recent OPYC version. The individual ice (and snow) surface temperature is derived from a linearized equation employing a Taylor series expansion of the total heat flux around $T_{\mathrm{s}}$.

While this represents a simplification compared to the SIBL thermodynamics, more complexity is introduced through the inclusion of heat accumulation in the snow and the ice layer with a concomitant determination of the temperature at the interface between snow and ice and of aging processes of snow parameterizing the metamorphosis of snow crystals to ice [Oberhuber, 1993b]. In the SIBL model, such processes are not accounted for. Specifically, there the temperature profile is assumed to be linear through the snow/ice layer, the insulation effect of snow being approximated by an equivalent ice thickness allowing for the lower thermal conductivity of snow [Owens and Lemke, 1990].

Other differences arise from the different numerical treatment, especially of the dynamic equations. While a semiimplicit method with a predictor-corrector stepping is employed in SIBL, the OPYC sea ice drift is predicted implicitly in one step. The momentum equation in SIBL is solved by a 
successive overrelaxation procedure with Chebyshev acceleration, while in the OPYC sea ice code this equation is solved by line relaxation applying the Gaussian elimination technique, the matrix coefficients being updated instantaneously during the iteration [Oberhuber, 1993b]. This method leads to slower convergence toward the solution but provides an improved balance of the strain rates (and thus viscosities), which are usually highly variable in space and time.

\section{Appendix C: HOPE Sea Ice Model}

The HOPE OGCM together with its sea ice component is described in detail by Wolff and Maier-Reimer [1993] and Drijfhout et al. [1996]. The main differences in this sea ice code compared to that in SIBL occur in the sea ice thermodynamics, which are basically the same as used in the LSG OGCM [Maier-Reimer et al., 1993]. They do not involve a heat balance calculation with determination of the ice surface temperature and they neglect any impact of snow. Instead, the ice growth formulation from Stefan [1891] is employed whenever the upper ocean and the air temperature is at or below the freezing temperature. Starting point is the ice growth equation:

$$
\frac{d h}{d t}=\frac{k}{\rho L}\left(T_{\mathrm{f}}-T_{\mathrm{a}}\right) / h
$$

where $k$ is thermal conductivity of sea ice, $L$ is latent heat of fusion, $T_{\mathrm{f}}$ is freezing temperature of seawater, and $T_{\mathrm{a}}$ is air temperature.

Equation (C1) is the same equation as used in SIBL and OPYC to calculate thermodynamic ice growth, except that there $T_{\mathrm{a}}$ is replaced by the diagnostically determined surface (skin) temperature of ice. Solving (C1) analytically yields Stefan's law [Leppäranta, 1993]:

$$
h^{2}=h_{0}^{2}+2 k \int_{0}^{\iota}\left[T_{\mathrm{f}}-T_{\mathrm{a}}(\tau)\right] d \tau /(\rho L)
$$

which explicitly leads to

$$
h^{2}=h_{0}^{2}+\left(2 k\left(T_{\mathrm{f}}-T_{\mathrm{a}}\right) / \rho L\right) t_{\mathrm{ell}}
$$

where $t_{\text {cff }}=\Delta t$, when $h=h_{0}$ at $t=0$ and $h_{0}>0$. This law is the principal description of the freezing process. The employment of the ambient air temperature as upper boundary condition for the ice growth equation, however, is critical, because it assumes that the effect of the individual heat fluxes involved in the surface heat balance is provided by the air temperature.

In cases where no ice is present initially (new-ice growth), the effective time for the time integral is taken as

$$
t_{\text {cll }}=\Delta t\left(T_{1}-T_{\mathrm{o}}^{\mathrm{new}}\right) /\left(T_{\mathrm{o}}^{\mathrm{old}}-T_{\mathrm{v}}^{\mathrm{new}}\right)
$$

in order to avoid excessive initial ice growth [see Maier-Reimer et al., 1993] (note that (C1) is strictly not applicable for $h_{0}=$ 0 ). New-ice growth in partially ice-covered grid cells is not explicitly accounted for.

Thermodynamic ice ablation is also treated differently from SIBL. The source of ice melt from the bottom is provided through heating of the upper ocean via the ice-free parts of a grid cell by the air temperature (the strength of the temperature forcing being determined by an empirical relaxation coefficient). Contrary to Maier-Reimer et al. [1993], this model version contains a solar radiation term which is directly im- posed on the ice-free and the ice-covered part of a grid cell as a supplement to (C1) [Drijfhout et al., 1996].

Further differences from SIBL are associated with different assumptions about thermodynamically induced changes of ice compactness. Lead closing in the HOPE (and LSG) model is determined by

$$
N^{\text {new }}=\left(N^{\text {old }}+F_{0} / h^{*}\right) /\left(1+F_{0} / h^{*}\right)
$$

where $F_{0}=\sqrt{\left(2 k\left(T_{\mathrm{f}}-T_{\mathrm{a}}\right) / \rho L\right) \Delta t}$ and $h^{*}=0.5 \mathrm{~m}$, which is principally similar to the empirical formulation given by Hibler [1979], except for the simplifications mentioned above concerning the surface heat budget. In case of new-ice formation the ice coverage per grid cell is given by $N^{\text {new }}=h^{\text {new }} / h^{*}$. Decreasing ice compactness in case of ice melt (decrease in ice thickness) is expressed as

$$
N^{\text {new }}=N^{\text {old }}\left(h^{\text {new }} / h^{\text {old }}\right)
$$

instead of

$$
N^{\text {new }}=N^{\text {old }}\left(h^{\text {new }}-h^{\text {old }}\right) /\left(2 h^{\text {old }}\right)+N^{\text {old }}
$$

as by Hibler [1979].

The numerical treatment of the sea ice dynamics of HOPE is essentially the same as in SIBL. Differences enter due to the application of an E grid instead of a B grid as in SIBL (and OPYC). This leads to a more efficient numerical treatment of the momentum equation, which is solved iteratively in a straightforward semi-implicit scheme. Specifically, the E grid configuration allows a direct spatial differentiation of the staggered grid points of the "even" grid using the neighboring values of the "odd" grid, thus avoiding any spatial averaging procedures as in the B grid discretization. In order to accelerate the convergence (which in the initial version was rather slow when daily wind variability was imposed), a predictorcorrector scheme with updated strain rates (similar to SIBL) was introduced.

Acknowledgments. The authors would like to thank K. Hasselmann and $\mathrm{L}$. Bengtsson for an internal review, S. S. Drijfhout, U. Sciler, J. Zhang, and A. Bacher for valuable discussions on the subject of this study. Wc also thank T. Crowley and two anonymous reviewers for their comments on an earlier version of the manuscript. The Deutsche Wetterdienst (DWD) provided the ECMWF data, which were preprocessed by R. Schnur. The major part of this work was accomplished at the Max-Planck-Institut fur Meteorologie in Hamburg. It was mainly sponsored by the Deutsche Forschungsgemeinschaft (DFG) via the SFB 318.

\section{References}

Allison, I., R. E. Brandt, and S. G. Warren, East Antarctic sea ice: Albedo, thickncss distribution, and snow cover. J. Goophys. Res., 98 , 12,417-12,429, 1993.

Andreas, E. L., and S. F. Ackley, On the differences in ablation seasons of Arctic and Antarctic sea ice, J. Atmos. Sci., 39, 440-447, 1982.

Arakawa, A., and V. R. Lamb, Computational design of the basic dynamical processes of the UCLA general circulation model, $\mathrm{Meth}$ ods Comput. Phys., 17, 173-265, 1977.

Bacastow, R., and E. Maier-Reimer, Ocean-circulation model of the carbon cycle, Cllm. Dyn., 4, 95-126, 1990.

Barry, R. G., M. C. Serreze, J. A. Maslanik, and R. H. Preller, The Arctic sea ice-climate system: Observations and modeling, Rev. Geophys., 31(4), 397-422, 1993.

Broecker, W. S., Oxygen isotope constraints on surface ocean temperature, Quat. Res., 26, 121-134, 1986.

Bryan, K., Climate and the ocean circulation, III, The ocean model, Mon. Weather Rev., 97, 806-827, 1969. 
Cubasch, U., K. Hasselmann, H. Höck, E. Maier-Reimer, U. Mikolajewicz, B. D. Santer, and R. Sausen, Time-dependent greenhouse warming computations with a coupled ocean-atmosphere model, Clim. Dyn., 8, 55-69, 1992.

Cubasch, U., B. D. Santer, A. Hellbach, G. Hegerl, H. Hóck, E. Maier-Reimer, U. Mikolajewicz, A. Stössel, R. Voss, Monte Carlo climate change forecasts with a global coupled ocean-atmosphere model, Clim. Dyn., 10, 1-19, 1994.

Curry, J. A., J. L. Schramm, and E. E. Ebert, Impact of clouds on the surface radiation balance of the Arctic Ocean, Meteorol. Atmos. Phys., 51, 197-217, 1993.

Drijfhout, S. S., C. Heinze, M. Latif, and E. Maier-Reimer, Mcan circulation and internal variability in an ocean primitive equation model, J. Phys. Oceanogr., 26, 559-580, 1996.

England, M. H., On the formation of Antartic intermediate and bottom water in ocean general circulation models, J. Phys. Oceanogr. 22, 918-926, 1992.

England, M. H., Representing the global-scale water masses in ocean general circulation models, J. Phys. Oceanogr., 23, 1523-1552, 1993.

Flato, G. M., and W. D. Hibler III, Modeling pack ice as a cavitating fluid, J. Phys. Oceanogr., 22, 626-651, 1992.

Foster, R. C., and R. A. Brown, On large-scale PBL modelling: Surface layer models, Global Atmos. Ocean Syst., 2, 185-198, 1994.

Gates, W. L., AMIP: The Atmospheric Model Intercomparison Project, Bull. Am. Meteorol. Soc., 73, 1962-1970, 1992

Gloersen, P., and W. J. Campbell, Variations in the Arctic, Antarctic and global sea ice covers during 1978-1987 as observed with the Nimbus 7 scanning multichannel microwave radiometer, J. Geophys. Res., 93, 10,666-10,674, 1988.

Gordon, A. L., and B. A. Huber, Southern Ocean winter mixed layer, J. Geophys. Res., 95, 11,655-11,672, 1990.

Gordon, A. L., S. F. Ackley, and T. Baker, Large-scale relative dynamic topography of the Southern Ocean, J. Geophys. Res., 83 3023-3032, 1978

Gray, J. M. N. T., and P. D. Killworth, Stability of the viscous-plastic sea ice rheology, J. Phys. Oceanogr., 25, 971-978, 1995.

Haapala, J., M. Lepparanta, and A. Omstedt, Data programme for Baltic sea ice climate modelling. Rep. Ser. Geophys. 27, pp. 95-107, Dep. of Geophys., Univ. of Helsinki, Helsinki, Finland, 1993.

Häkkinen, S., Simulated interannual variability of the Greenland Sea deep water formation and its connection to surface forcing, J. Geophys. Res., 100, 4761-4770, 1995.

Hàkkinen, S., and G. L. Mellor, Modeling the seasonal variability of a coupled arctic ice-ocean system, J. Geophys. Res., 97, 20,285-20,304, 1992.

Hibler, W. D., III, A viscous sea ice law as a stochastic average of plasticity, J. Geophys. Res., 82, 3932-3938, 1977.

Hibler, W. D., III, A dynamic thermodynamic sea ice model, J. Phys. Oceanogr., 9, 815-846, 1979.

Hibler, W. D., III, and S. F. Ackley, Numerical simulation of the Weddell Sea pack ice, J. Geophys. Res., 88, 2873-2887, 1983.

Hibler, W. D., III, and K. Bryan, A diagnostic ice-ocean model, J. Phys. Oceanogr., 17, 987-1015, 1987.

Holland, D. M., and J. M. Oberhuber, Some numerical issues relating to the simulation of sea ice, NATO ASI Ser. I, 12,653-673, 1995.

Holland, D. M., L. A. Mysak, D. K. Manak, and J. M. Oberhuber, Sensitivity study of a dynamic thermodynamic sea ice model, $J$. Geophys. Res., 98, 2561-2586, 1993.

Intergovernmental Panel on Climate Control (IPCC), Technical summary, in Climate Change 1995: The Science of Climate Change, Contribution of Working Group I, edited by J. T. Houghton et al., pp. 9-49, Cambridge Univ. Press, New York, 1995.

Laevastu, T., Factors affecting the temperature of the surface layer of the sea, Comment. Phys. Math., 25, 1-136, 1960.

Latif, M., T. Stockdale, J.-O. Wolff, G. Burgers, E. Maier-Reimer, M. M. Junge, K. Arpe, and L. Bengtsson, Climatology and variability in the ECHO coupled GCM, Tellus, Ser. A., 46, 351-366, 1994.

Legutke, S., E. Maier-Reimer, U. Cubasch, A. Stóssel, and A. Hellbach, A coupled world ocean-sea ice model, WMO CAS/JSC Rep. 21 World Meteorol. Org., Geneva, 1996.

Lemke, P., W. B. Owens, and W. D. Hibler III, A coupled sea icemixed layer-pycnocline model for the Weddell Sea, J. Geophys. Res. 95, 9513-9525, 1990.

Lepparanta, M., A review of analytical models of sea-ice growth, Atmos. Ocean, 31, 123-138, 1993.

Lepparanta, M., and W. D. Hibler III, The role of plastic ice interac- tion in marginal ice zone dynamics, J. Geophys. Res., 90, 11,899$11,909,1985$.

Lunkeit, F., R. Sausen, and J. M. Oberhuber, Climate simulations with the global coupled atmosphere-ocean model ECHAM2/OPYC, I, Present-day climate and ENSO events, Clim. Dyn., 12, 195-212, 1996.

Maier-Reimer, E., The driving force of brine rejection on the deepwater formation in the Hamburg LSG OGCM, NATO ASI Ser. I 12,211-12,216, 1993.

Maier-Reimer, E., U. Mikolajewıcz, and K. Hasselmann, Mean circulation of the Hamburg LSG OGCM and its sensitivity to the thermohaline surface forcing, J. Phys. Oceanogr., 23, 731-757, 1993.

Manabe, S., M. J. Spelman, and R. J. Stouffer, Transient responses of a coupled ocean-atmosphere model to gradual changes of atmospheric $\mathrm{CO}_{2}$, II, Seasonal response, J. Clım. 5, 105-126, 1992.

Martinson, D. G., Evolution of the Southern Ocean winter mixed laye and sea ice: Open ocean deepwater formation and ventilation, $J$. Geophys. Res., 95, 11,641-11,654, 1990.

Maykut, G. A., The surface heat and mass balance, NATO ASI Ser., Ser. B, 146, 395-464, 1986.

Meehl, G. A., and W. M. Washington, $\mathrm{CO}_{2}$ climate sensitivity and snow-sea ice albedo parameterisation in an atmospheric GCM coupled to a mixed-layer ocean model, Clim. Change, 6, 283-306, 1990.

Mikolajewicz, U., B. D. Santer, and E. Maier-Reimer, Ocean response to greenhouse warming, Nature, 345, 589-593, 1990.

Mysak, L. A., D. K. Manak, and R. F. Marsden, Sea-ice anomalies observed in the Greenland and Labrador Seas during 1901-1984 and their relation to an interdecadal Arctic climate cycle, Clim. Dyn., 5, 111-133, 1990.

Oberhuber, J. M., Simulation of the Atlantic circulation with a coupled sea ice-mixed layer-isopycnal general circulation model, I, Model description, $J$. Phys. Oceanogr., 23, 808-829, 1993a.

Oberhuber, J. M., The OPYC ocean general circulation model, Tech. Rep. 7, Rev. 1, Deutsches Klimarechenzentrum, Hamburg, Germany, $1993 \mathrm{~b}$.

Olbers, D., and C. Wübber, The role of wind and buoyancy forcing of the Antarctic circumpolar current, in Strategies for Future Climate Research, pp. 161-192, Max-Planck-Inst. für Meteorol., Hamburg, Germany, 1991.

Owens, W. B., and P. Lemke, Sensitivity studies with a sea ice-mixed layer-pycnocline model in the Weddell Sea, J. Geophys. Res., 95(C6), 9527-9538, 1990.

Parkinson, C. L., and W. M. Washington, A large-scale numerical model of sea ice, J. Geophys. Res., 84(C1), 311-337, 1979.

Piacsek, S., R. Allard, and A. Warn-Varnas, Studies of the Arctic ice cover and upper ocean with a coupled ice-ocean model, J. Geophys. Res., 96, 4631-4650, 1991.

Pierce, D. W., T. P. Barnett, and U. Mikolajewicz, Competing roles of heat and freshwater flux in forcing thermohaline oscillations, J. Phys. Oceanogr., 25, 2046-2064, 1995.

Pollard, D., and S. L. Thompson, Sea-ice dynamics and $\mathrm{CO}_{2}$ sensitivity in a global climate model, Atmos. Ocean, 32, 449-467, 1994.

Reed, R. K., On estimating insolation over the ocean, J. Phys. Oceanogr., 7, 482-485, 1977.

Semtner, A. J., Jr., A numerical study of sea ice and ocean circulation in the Arctic, J. Phys. Oceanogr., 17, 1077-1099, 1987.

Semtner, A. J., Jr., and R. M. Chervin, Ocean general circulation from a global eddy-resolving model, J. Geophys. Res., 97, 5493-5550, 1992.

Stefan, J., Über die Theorie der Eisbildung, inbesondere über Eisbildung im Polarmeere, Ann. Phys., 3(42), 269-286, 1891.

Stössel, A., Application of an atmospheric boundary-layer model to a large-scale coupled sea-ice-oceanic mixed-layer model for the Southern Ocean, Ann. Glaciol., 15, 191-195, 1991.

Stóssel, A., Sensitivity of Southern Ocean sea-ice simulations to different atmospheric forcing algorithms, Tellus, Ser. A, 44, 395-413, 1992.

Stossel, A., and M. Claussen, On the momentum forcing of a largescale sea-ice model, Clim. Dyn., 9, 71-80, 1993

Stoossel, A., and W. B. Owens, The Hamburg sea-ice model, Tech. Rep. 3, Rev. 1, Deutsches KlimaRechenZentrum, Hamburg, Germany, 1992.

Stössel, A., P. Lemke, and W. B. Owens, Coupled sea ice-mixed layer simulations for the Southern Ocean, J. Geophys. Res., 95, 9539-9555, 1990.

Toggweiler, J. R., and B. Samuels, Is the magnitude of the deep 
outflow from the Atlantic Ocean actually governed by southern hemisphere winds? NATO ASI Ser., Ser. I, 15, 303-331, 1993.

Toggweiler, J. R., and B. Samuels, Effect of sea ice on the salinity of Antarctic bottom waters, J. Phys. Oceanogr., 25, 1980-1997, 1995.

Wadhams, P., M. A. Lange, and S. F. Ackley, The ice thickness distribution across the Atlantic sector of the Antarctic ocean in midwinter, J. Geophys. Res., 92, 14,535-14,552, 1987.

Walsh, J. E., W. D. Hibler, and B. Ross, Numerical simulation of northern hemisphere sea ice variability, 1951-1980, J. Geophys. Res. 90, 4847-4865, 1985.

Washington, W. M., G. A. Meehl, L. VerPlank, and T. W. Bettge, A world ocean model for greenhouse sensitivity studies: Resolution intercomparison and the role of diagnostic forcing, Clim. Dyn., 9 321-344, 1994.

Whitworth, T., III, The Antarctic circumpolar current, Oceanus, 31 $53-58,1988$.

Wolff, J.-O., and E. Maier-Reimer, HOPE The Hamburg Ocean Prim- itive Equation model; Cycle 1, technical report, Deutsches KlimaRechenZentrum, Hamburg, Germany, 1993.

Zwally, H. J., J. C. Comiso, C. L. Parkinson, F. D. Carsey, W. J. Campbell, and P. Gloersen, Antarctic sea ice 1973-1976: Satellite passive-microwave observations, NASA Spec. Publ., SP-459, 1983.

E. Maier-Reimer, Max-Planck-Institut für Meteorologie, Bundesstr. 55, 20146 Hamburg, Germany. (e-mail: maier-reimer@dkrz.de)

J. M. Oberhuber, Deutsches Klimarechenzentrum, Max-Planck-Inst. für Meteorologie, Bundesstr. 55, 20146 Hamburg, Germany. (e-mail: oberhuber@dkrz.de)

A. Stössel, Department of Oceanography, Texas Center Climate Studies, Texas A\&M University, College Station, TX 77843-3146. (e-mail: achim@advect.tamu.edu)

(Received May 30, 1995; revised April 23, 1996; accepted May 2, 1996.) 